EUROPEAN CENTRAL BANK

\title{
PUBLIC AND PRIVATE
} SECTOR WAGES

\section{CO-MOVEMENT AND}

\section{CAUSALITY}

by Ana Lamo, Javier J. Pérez and Ludger Schuknecht

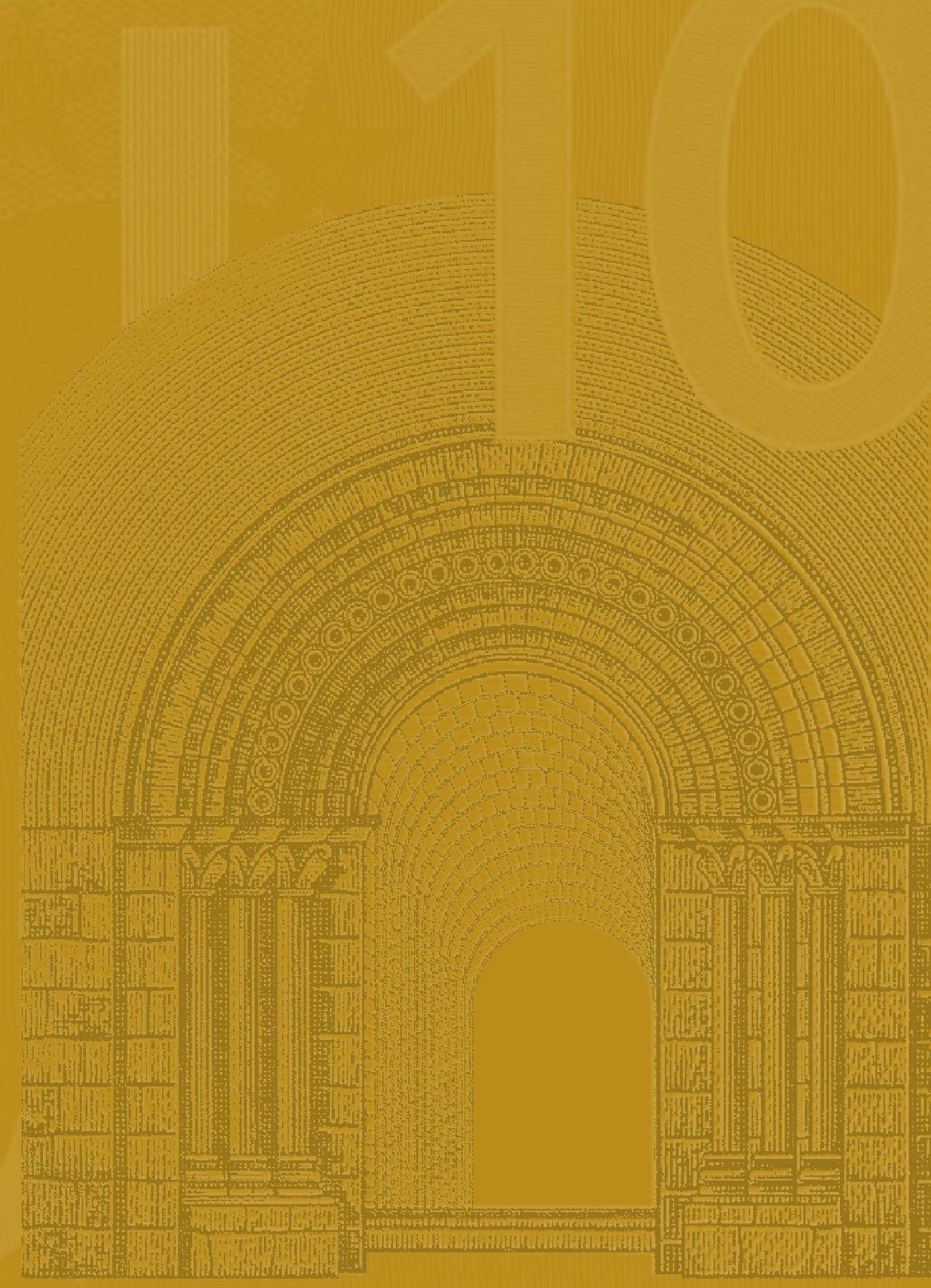




\section{WORKING PAPER SERIES} NO 963 / NOVEMBER 2008

WAGE DYNAMICS

NETWORK

PUBLIC AND PRIVATE SECTOR

WAGES

CO-MOVEMENT AND

CAUSALITY'

by Ana Lamo², Javier J. Pérez ${ }^{3}$

and Ludger Schuknecht ${ }^{2}$

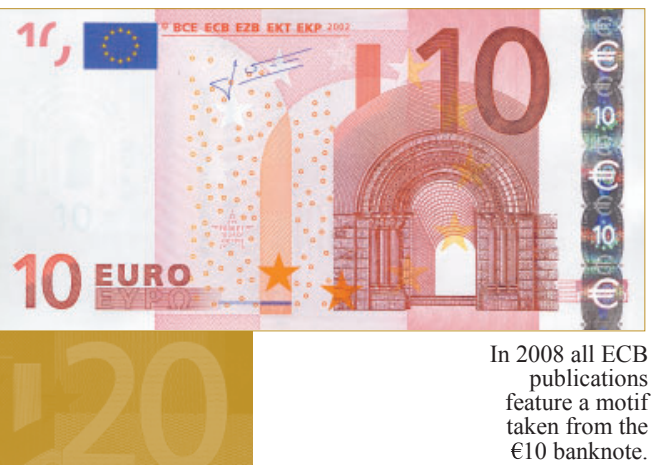

This paper can be downloaded without charge from http://www.ecb.europa.eu or from the Social Science Research Network electronic library at http://ssrn.com/abstract_id=|29|I/2.

I The views expressed in this paper are those of the authors and do not necessarily reflect those of the European Central Bank (ECB) and the Bank of Spain. Thanks are due to J. von Haguen, H. Lebihan, D. Pedregal, A. van Riet, C. Robalo Marques, P. Rother, A. J. Sánchez, F. Smets and participants at the Wage dynamics Network (WDN) Macro Group meeting on 20 February 2007 for helpful comments. 2 European Central Bank, Kaiserstrasse 29, D-603II Frankfurt am Main, Germany; e-mail: ana.lamo@ecb.europa.eu; ludger.schuknecht@ecb.europa.eu 3 Banco de España, Alcalá 50, E-28014 Madrid, Spain; e-mail: javierperez@bde.es 


\section{Wage Dynamics Network}

This paper contains research conducted within the Wage Dynamics Network (WDN). The WDN is a research network consisting of economists from the European Central Bank (ECB) and the national central banks (NCBs) of the EU countries. The WDN aims at studying in depth the features and sources of wage and labour cost dynamics and their implications for monetary policy. The specific objectives of the network are: i) identifying the sources and features of wage and labour cost dynamics that are most relevant for monetary policy and ii) clarifying the relationship between wages, labour costs and prices both at the firm and macro-economic level.

The WDN is chaired by Frank Smets (ECB). Giuseppe Bertola (Università di Torino) and Julian Messina (Universitat de Girona) act as external consultants and Ana Lamo (ECB) as Secretary.

The refereeing process of this paper has been co-ordinated by a team composed of Gabriel Fagan (ECB, chairperson), Philip Vermeulen (ECB), Giuseppe Bertola, Julian Messina, Jan Babecký (CNB), Hervé Le Bihan (Banque de France) and Thomas Mathä (Banque centrale du Luxembourg).

The paper is released in order to make the results of WDN research generally available, in preliminary form, to encourage comments and suggestions prior to final publication. The views expressed in the paper are the author's own and do not necessarily reflect those of the ESCB.

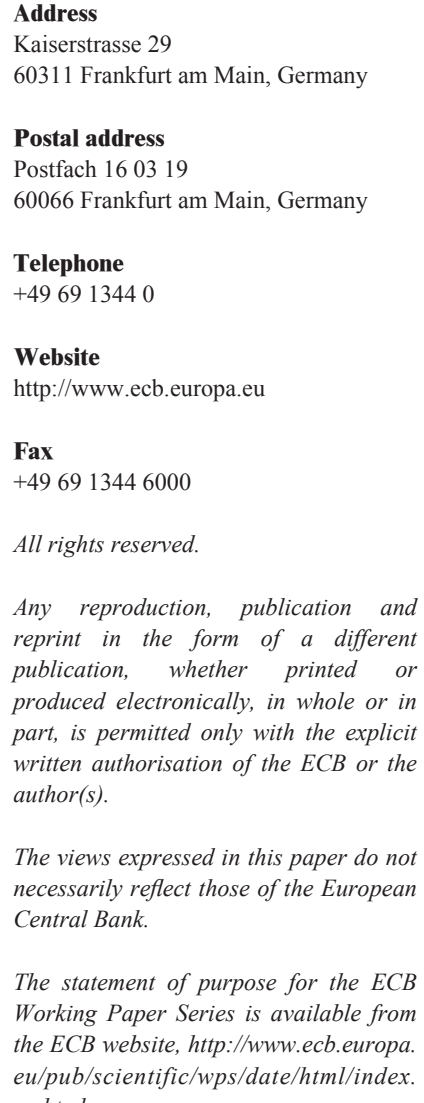




\section{CONTENTS}

Abstract

Non-technical summary

1 Introduction

2 The literature

9

3 Data and stylised facts

3.1 Data sources and definition of variables

3.2 Some stylised facts on public wages

4 The co-movement of public and private sector wages over the business cycle

4.1 Methodology

5 Medium- and long-run co-movements, and co-integration

5.1 den Haan's medium- and long-term co-movements

5.2 Long-run relationship (co-integration)

6 Who is in the driver seat?

6.1 Empirical specification

6.2 Causality analysis

6.3 Public wage leadership and wage setting institutions

7 Conclusions

References

Tables and figures

Appendices

European Central Bank Working Paper Series 


\begin{abstract}
This paper looks at public and private sector wages interactions since the $1960 \mathrm{~s}$ in the euro area, euro area countries and a number of other OECD countries. The paper reports, first, a strong positive annual contemporaneous correlation of public and private sector wages over the business cycle; this finding is robust across methods and measures of wages and quite general across countries. Second, we show evidence of long-run relationships between public and private sector wages in all countries. Finally, causality analysis suggests that feedback effects between private and public wages occur in a direct manner and, importantly also via prices. While influences from the private sector appear on the whole to be stronger, there are direct and indirect feedback effects from public wage setting in a number of countries as well. We show how country-specific institutional features of labour and product markets contain helpful information to explain the heterogeneity across countries of our results on public/private wage leadership.
\end{abstract}

Keywords: government wages; private sector wages; causality; co-movement.

JEL Classification: C32; J30; J51; J52; E62; E63; H50. 


\section{Non-technical Summary}

This paper empirically analyses the interaction between public and private sector wages for the euro area and a number of other OECD countries over the period 1960-2006. It looks at the two related issues of co-movement and causal linkages.

This issue is interesting from an analytical and a policy perspective, notably in the euro area. Wage spillovers across sectors of an economy might lead to wage costs growing faster than productivity or than other fundamentals in some sectors and may affect international cost competitiveness of countries' tradable sectors. In this regards, the interaction between public sector wages with the wages of the rest of the economy deserves a separate treatment for several reasons. First, public wages and employment comprise almost one quarter of the total dependent work force and total compensation of employees in the OECD. Second, public wages are not necessarily determined by market forces to the same extent as wages in the private sector. The wage setting behaviour of the public sector is likely to differ from that of the private sector due to a number of factors such as a higher degree of unionisation, political objectives, the difficulties of measuring labour productivity in the public sector, the different status that civil servants enjoy and that might make public wages less reactive to the business cycle, or the separate agenda of public employees (rent-seeking behaviour). In addition, there may be institutional linkages between private and public labour market behaviour. Needless to say that the subject is also highly relevant from a monetary policy perspective.

The theoretical and empirical literature on job market interactions between the public and the private sector is surprisingly scarce, and provides limited guidance as to the expected dominant mechanisms linking public and private wages, or the expected sign of the correlation between wages in different sectors. On the empirical front, the few available papers focus on a particular country (mainly Sweden plus a few others) and tend to find evidence supporting the hypothesis that the private sector is the (nominal) wage leader, while at the same time they find limited support for the opposite causal direction (public sector wages cause private sector wages).

To obtain the most robust results possible, we apply a number of alternative empirical methodologies, and perform the analysis for two data samples and different price deflators. The paper provides, firstly, empirical evidence on the correlation of public and private wages over the business cycle. The study finds that in the euro area and most of the countries of our sample private wages are positively and strongly correlated with public wages over the business cycle mostly contemporaneously. Our findings appear quite robust both across countries and periods (1960-2006 and 1980-2006).

Secondly, the paper finds short- medium and long-run co-movements between public and private sector wages. For the short-run correlations, the results of the previous (robust) analysis are confirmed. For the co-movements at longer frequencies than the standard business cycle, our results show a strong correlation between public and private sector wages. Thirdly, (and unsurprisingly) the paper reports 
the existence of a long-run relationship between public and private sector wages in all the countries of the analysed sample. Wages in both sectors share a common driving trend that can be interpreted as a combination of long-run trends in prices and aggregate productivity.

Fourthly, the paper conducts a thorough analysis of causality. We run causality tests for different transformations of the nominal and deflated wage variables. a) We look at VARs between detrended variables (using eleven detrending methods), and thus focus on the Granger-causal links over the business cycle. We find a dominant pattern of private sector wage leadership over the business cycle for nominal wages and a number of cases of bi-directional causality. When prices are explicitly taken into account, the dominant private sector lead vanishes, suggesting that the price level is an important adjustment parameter. Moreover, there is evidence of some leading behaviour from the public to the private sector. We also run VARs in levels (logs) of the variables which broadly confirm the findings of the first approach. A first look at the role of prices seem to indicate that there are significant feedback effects from private wages on the price level which we find for all countries plus the euro area aggregate. While this influence can also be found for public wages, the evidence is in many cases weaker and depends on the deflator. We show how country-specific institutional features of labour and product markets contain helpful information to explain the heterogeneity across countries of our results on public/private wage leadership.

From a policy perspective, we can conclude: public and private wages do not decouple. Private sector wages seem to exert mostly a stronger influence on public wages than the other way around. However, on the whole and in a number of countries results of correlation and causality analysis also suggest an important influence from the public sector on private wages both directly and indirectly via prices. This has important policy implications in that private but also public wage setting are important for overall wage and competitiveness developments. Moreover, second round effects seem to play an important role in wage and prices dynamics. 


\section{Introduction}

This paper empirically analyses the interaction between public and private sector wages for the euro area and a number of other OECD countries over the period 1960-2006. It looks at the two related issues of co-movement and causal linkages between public and private sector wages.

This issue is relevant from an analytical and a policy perspective, notably in the euro area. Wage spillovers across sectors of an economy might lead to wage costs growing faster than productivity or than other fundamentals in some sectors and may affect international cost competitiveness of countries' tradable sectors. In this regards, the interaction between public sector wages with the wages of the rest of the economy deserves a separate treatment for several reasons. First, public wages and employment comprise almost one quarter of the total dependent work force and total compensation of employees in the OECD. Second, public wages are not necessarily determined by market forces to the same extent as wages in the private sector. The wage setting behaviour of the public sector is likely to differ from that of the private sector due to a number of factors such as a higher degree of unionisation, political objectives, ${ }^{1}$ the difficulties of measuring labour productivity in the public sector, the different status that civil servants enjoy and that might make public wages less reactive to the business cycle, or the separate agenda of public employees (rent-seeking behaviour). ${ }^{2}$

In addition, there may be institutional linkages between private and public labour market behaviour. First, there may be direct links via the wage bargaining process. If by design the government is the wage "leader", it is likely that the private sector will follow more the government than market processes (at least in the short run) and quantities (private employment) are likely to adjust. If the private sector is the wage "leader" it is more likely that prices (wages) adjust which, in turn, reduces incentives for quantity adjustment. Second, there may be more indirect institutional linkages. If social

\footnotetext{
${ }^{1}$ Government employment and wage decisions may indeed depart from the standard profit maximisation behaviour expected in the private sector. As discussed by Gregory and Borland (1999) or Forni and Giordano (2003), there are two main theoretical approaches in the literature to understanding how public employer's decisions are taken. One approach treats public sector decision-makers as making choices to achieve socially optimal outcomes; the alternative approach introduces some personal objective of the politicians. Public sector decision-makers that seek to maximise social welfare may have both efficiency goals (minimise the cost of production of output in the public sector, or resolve labor market imperfections) but also equity goals (for example use public employment as a redistribution tool, as signalled by Alesina, Danninger and Rostagno, 2001, and Alesina, Baquir and Easterly, 2000).

${ }^{2}$ For example, to explain increasing public employment in developing countries Gelb et al. (1991) state that in line with theories of rent seeking behaviour, public sector surplus is viewed as the consequence of lobbying for higher wages and employment. As regards developing countries, the data seem to confirm the predictions of rent-seeking theories: there appear to be little correlation between public and private sector wages (Agénor, 1995). An alternative hypothesis is provided by Rodrick (2000): relatively safe government jobs represent partial insurance against undiversifiable external risks faced by some developing economies. On different grounds, Matschke (2003) shows empirical evidence of public employees' pressure in Germany ahead of political elections.
} 
benefits and minimum wage levels are tied to wage developments in the public sector, then these indirectly influence private wage setting, even if wage bargaining is "officially" independent. Finally, not only the direct interaction between public and private wages has repercussions on inflation but there is also evidence of indirect feedback effects via prices. For example, public wage shocks may raise the inflation rate which in turn could lead to increases in private (and further increases in public) wages. From this perspective the subject might turn out to be also highly relevant from a monetary policy perspective.

Our study analyses the interaction between public and private wages in many industrialised countries: the euro area aggregate, ten euro area countries (Germany, France, Italy, Spain, Netherlands Austria, Belgium, Greece, Ireland, Portugal, Finland), Sweden, Denmark, Norway, United States, United Kingdom, Canada and Japan. Using annual data (for the period 1960-2006) is imposed by the absence of quarterly data for the variables in this study for most of the European countries in the sample. We also look at the results for the sample 1980-2006, given an apparent change in trend around 1980 in public employment.

The study aims to obtain the most robust results possible, by examining nominal wages, and also nominal wages deflated with two alternative price deflators (private consumption deflator and GDP deflator), by using a large number of detrending techniques, and by applying a host of approaches to correlation, co-movement and causality over different time horizons.

The paper provides, firstly, robust empirical evidence on the correlation of public and private wages over the business cycle. We look at the unconditional correlations between detrended series (at the standard business cycle frequencies) using eleven methods. The study finds that in the euro area and for most of the countries of our sample private wages are positively and strongly correlated with public wages over the business cycle in a mostly contemporaneous manner. This is a very robust result across countries, in spite of very different institutional settings and different inflation regimes witnessed in the different decades covered by our study.

Secondly, the paper provides an analysis of short-, medium-, and long-run co-movements between public and private sector wages using the methodology of den Haan (2000). For the short-run correlations the results of the previous (robust) analysis are confirmed. For the co-movements at longer frequencies than the standard business cycle frequencies our results show a strong correlation between public and private sector wages. Thirdly, following up on these pieces of evidence, the paper reports the existence of a long-run relationship (co-integration) between public and private sector wages in all the countries of the analysed sample. Wages in both sectors share a common driving trend.

Moreover, the paper conducts a thorough analysis of causality. We run Granger-Causality tests for different empirical specifications comprising nominal wage variables and the price level. First, we 
focus on the Granger-causal links over the business cycle by looking at VARs between detrended variables (using eleven detrending methods). Second, we run VARs in levels (logs) of the variables, as suggested by Toda and Yamamoto (1995) and Dolado and Lütkephol (1996). The analysis suggests that feedback effects between private and public wages occur in a direct manner and, importantly also via prices. While influences from the private sector appear on the whole to be stronger, there are direct and indirect feedback effects from public wage setting in a number of countries. Third, we carry out an empirical exercise aiming at understanding the rationale behind the heterogeneity across countries of our results on causality, i.e. why in some instances we find private sector wages Granger-causing public sector wages and in others the opposite direction of causation. We show how country-specific institutional features of labour and product markets contain helpful information to explain the heterogeneity across countries of our results on public/private wage leadership.

The paper is organised as follows. Following a brief literature survey in Section 2, we describe the data set and some stylised facts on the developments of public wages for the period 1960-2006 in section 3. Section 4 looks at the co-movements of public and private wages over the business cycles, while section 5 analyses medium- and long-term co-movements and co-integration. Section 6 looks at the causal relationships between the two sectors and the link to labour and product market institutional features. Section 7 concludes and provides some policy implications and avenues for further research.

\section{The literature}

The literature has so far paid very limited attention to the correlation between public and private wages. In theoretical models (real) public wages are assumed to be exogenous or to follow the same determination patterns as private wages (Quadrini and Trigari, 2007, Ardagna, 2007, Holmund, 1997, or Calmfors and Horn, 1986). On related grounds Demekas and Kontolemis (2000) develop a static model in which increases in government wages lead through the worker flow channel to increases in private sector wages. The existing empirical work focuses on quantity links (employment) rather than price links (wages) between the public and the private sector. ${ }^{34}$ An exception would be Afonso and Gomes (2008) who conduct a pooled analysis of public and private sector wage growth in OECD and European Union countries. The authors find that nominal and deflated compensation per public sector employee display a statistically significant positive contemporaneous correlation with private sector wages.

\footnotetext{
${ }^{3}$ Alesina et al. (2002) find a sizeable negative effect of public spending and in particular of its wage component (wage bill) on private sector profits and on business investment. Ardagna (2007) claims that the latter results are consistent with the different theoretical models in which government employment creates wage pressure for the private sector, and thus can be used as anecdotal evidence supporting that the direction of causality would go from public sector wages and employment to private sector wages and employment. She claims that this supports her theoretical assumption of exogenous public wages and employment.

${ }^{4}$ See for example Algan, Cahuc and Zylberberg (2002) or Forni and Giordano (2003), and the literature quoted therein.
} 
The main theoretical reference as regards expected causality is the so-called Scandinavian model of inflation that assumes that the traded-goods sector is the wage leader, i.e. that wage leadership is exerted by the sectors that are more open to competition (see for example Strom, 1997). Bemmels and Zaidi (1990) look at Canadian industries and find a confirmation of the Scandinavian model, namely the tradable sector leading wage setting. Nevertheless, this model is sometimes at odds with the empirical literature. In the case of public/private wages sectoral interactions Friberg (2007) does not find evidence of the Scandinavian model for Sweden (along these lines see also Holmlund and Ohlsson, 1992, and Tagtstrom, 2000). In response to Friberg, Lindquist and Vilhelmsson (2004) apply a vector error correction approach to wage setting in Sweden with annual data for the period 19702002, and find long run wage leadership of the private sector and no Granger causation from the public to the private sector in the short run, in line with the results already obtained by Jacobson and Ohlsson (1994).

Apart from the case of Sweden, country studies on public-private sector wages causality are also scarce. Demekas and Kontolemis (1999) find weak exogeneity of real government wages for private sector behaviour in a VAR analysis for Greece (1971-1993). For Chile, Mizala and Romaguera (1995) find evidence of the private sector leading public wages after labour market liberalisation in the early 1980s. An IMF report for Romania (see Christou, Klemm and Tiffin, 2007) shows a bi-directional relationship between private and public wages using monthly data for 1993-2006; it also finds that government wages lead those in state-owned enterprises which, in turn, influence private wages.

\section{Data and stylised facts}

\subsection{Data sources and definition of variables}

We use a standard OECD dataset that has been used in related studies like Algan, Cahuc and Zylberberg (2002), Alesina et al. (2002), Lane (2003), or Lamo, Pérez and Schuknecht (2007), among others. In particular we use the OECD Economic Outlook database December 2007 Issue. Missing variables for some specific time periods/variables in this issue of the OECD have been completed with information coming from the Spring 2007, the Spring 2006, and the Spring 2005 issues.

Regarding the measures of wages we take compensation of employees and compensation per employee both in nominal and real terms. Given that deflators have been pointed out as a source of disparity of results in the empirical literature on cyclicality of wages (Abraham and Haltiwanger, 1995), we use two different indices to deflate nominal wages, namely the private consumption deflator and GDP deflator. We compute compensation per employee using compensation of employees and employment data. Compensation of private sector employees is defined as total economy 
compensation of employees minus compensation of government employees. Compensation per private employee is defined as private compensation of employees divided by private sector employees minus government employment minus self-employment. ${ }^{5}$

The concept of total compensation of employees in the government sector is a well-defined statistical concept and in particular for European countries it is a homogeneous concept as defined by the European System of National Accounts (ESA95). A different story applies to government employment, needed to compute compensation per employee, especially for European countries. EU member states do not report to Eurostat (the EU's statistical agency) standardized employment figures for the general government sector. Thus it is necessary to resort to national sources, and the issue of homogeneity across countries is more delicate. The OECD presents the best choice as regards crosscountry availability and homogeneity of data in this respect. For statistical issues regarding the definition of government employment see OECD (1997). ${ }^{6}$

\subsection{Some stylised facts on public wages}

When looking at developments in wages per employee, it is noteworthy that public and private wages in the euro area converged between the 1960s and the late 1980s before diverging again in more recent years with public wages at increasingly higher levels than private wages (Figure 1, panel 1). By contrast, in the US this ratio has fluctuated relatively little over recent decades. Within the euro area, France (with one of the highest public employment ratios) also features a broadly constant ratio, with public and private wages at similar levels (Figure 1, panel 2). In other euro area countries private wages tend to be lower than public wages per employee. ${ }^{7}$

Private wages grew much more strongly than in the public sector until about 1990 before this pattern reversed (Figure 2). The pattern of US wage developments was similar to the euro area in the 1970s and in most recent years but not in between. Figure 2 also reflects the different behaviour of public

\footnotetext{
${ }^{5}$ The euro area aggregate excludes Luxembourg, Slovenia, Cyprus and Malta, due to lack of data for these countries.

${ }^{6}$ Within the ESA95 framework, a rough proxy allowing for a homogeneous measure of the public sector wage bill consistent with a corresponding measure of public employment is to be found by adding the items "Public Administration and defence", "Health and social work" and "Education" (NACE classifications L, M and N). Nevertheless, this proxy is far from being appropriate for a our study, to the extent that part of compensation of employees and employment under the items "Health and social work" and "Education" do include activities that should be labelled under market/private services. In this respect, it could also vary markedly across euro area member states. Another source of concern with this source is the heterogeneous availability of data across countries and the limited sample size available.

${ }^{7}$ Private and public wage patterns are a mirror image of employment patterns. High public employment coupled with proportionate wages per employee might unveil a higher low skill concentration in the public sector. Domeij and Ljungqvist (2006) report that the dramatic decline of the skill premium in Sweden since the 1970s is the result of an expanding public sector, with the expansion taking the form of drawing low-skilled workers into local government jobs that service the welfare state.
} 
employment between the euro area and the US. Euro area public employment growth was very strong in the early observation period and below that of the private sector more recently. US public employment growth was broadly in line with that of the private sector over recent decades. Figure 2 also shows that the public sector in the euro area has displayed a much more stable hiring behaviour and job security (in terms of annual employment growth rates) than the private sector. By contrast, there is not much difference in the volatility of euro area public and private wages per employee (in annual growth rates). Hence, signs of interaction between the two sectors are more likely to be found on the wages side. US public employment growth appears much more volatile than in Europe and almost as volatile as that in the private sector.

\section{The co-movement of public and private sector wages over the business cycle}

\subsection{Methodology}

In this section we focus on co-movements of detrended measures of public and private wages, as it is general practice in the empirical business cycle literature, using a variety of detrending methods. Following standard practice we measure the co-movement between two series using the cross correlation function (CCF thereafter). For each pair of variables, the CCF computed using different detrending methods yield different information. Deciding that one of them is the preferred one, independently of the criteria used to take the decision, will discard useful information contained in the CCFs that are not selected. To avoid this, we take an agnostic approach by applying the idea of thick modelling as proposed by Granger and Jeon (2004). We combine the correlation coefficients following David (1949) and use Fisher transformations to normalize their distribution and stabilize their variance. ${ }^{8}$ The transformed coefficients can then be averaged as usual. Once the average is computed, we need to undo the Fisher transformation to get the correlation coefficient that summarizes the information contained in the combined correlation coefficients. This transformation greatly reduces the skew in the distribution, potentially yielding a more accurate estimate of the population correlation. In addition, the result of the transformation is minimally biased in small samples. ${ }^{9}$

As regards detrending methods, we use a variety of filters. The underlying assumption to detrending filters is that aggregate seasonally-adjusted economic time series can be decomposed into a trend component $T_{t}$, the so-called cyclical component $C_{t}$ that fluctuates around the trend, and an

\footnotetext{
${ }^{8}$ The standard approach in the literature is to just take one single detrending method and base the subsequent analysis on the detrended time series computed using that detrending method. A significant deviation from this practice is Lamo, Pérez and Schuknecht (2007), which serves as a model for this Section of the paper. Camacho, Pérez-Quirós and Sainz (2006) and Lamo, Pérez and Schuknecht (2007) also use Fisher transformations to combine correlation coefficients.

${ }^{9}$ Following Ganger and Jeon's suggestion, we exclude from the combined measure methods yielding extreme results (we exclude methods yielding a relative volatility above 10 ).
} 
unpredictable random component $\varepsilon_{t}$, i.e. a given series $y_{\mathrm{t}}$ can be decomposed as $y_{\mathrm{t}}=T_{\mathrm{t}}+C_{\mathrm{t}}+\varepsilon_{t}$. Most of the detrending filters take out the trend component from the original time series, so that both the cyclical and irregular components $C_{t}+\varepsilon_{t}$ are taken as measure of the cycle. Among these standard detrending methods we take the following (see Appendix A for a brief description): (i) first difference filter; (ii) deterministic trends; (iii) Hodrick-Prescott filter (with two different band-pass parameters); (iv) Band pass filter (with two different band-pass parameters); (iv) Unobserved components models: we estimate up to 5 different models that differ in the model of the trend and the cycle, including linear trend plus fixed-period cycle, local level model plus fixed-period cycle, local linear trend model plus fixed-period cycle, local level model plus estimated-period cycle, local linear trend model plus estimated-period cycle. The models allow for cycles of 2 to 6 years to be estimated (not just imposed as in the basic case) using the so-called DHR (Dynamic Harmonic Regression) methods as in Young, Pedregal and Tych (1999).

\subsection{Results}

Table 1 gives an overview of the results for all the analysed countries. ${ }^{10}$ It shows the co-movement results for total compensation per private and public employees, both for the variables in nominal terms and in real terms (deflated using the two selected deflators), for the two considered samples (1960-2006 and 1980-2006).

Each row of this table displays the robust CCF between a measure of detrended private wages at time $\mathrm{t}$, and a measure of detrended public wages at time $\mathrm{t}-\mathrm{k}$. Following the standard discussion in the literature, it is said that the two variables commove in the same direction over the cycle if the maximum value in absolute terms of the estimated correlation coefficient of the detrended series (call it dominant correlation) is positive, that they co-move in opposite directions if it is negative, and that they do not co-move if it is close to zero. We take maximum values of the combined correlations in the ranges $0.20-0.39$ and $0.40-0.49$ as evidence of weak and moderate correlation respectively. We refer to strong correlation if in absolute terms it is larger or equal to 0.50 . The cut-off point 0.20 was chosen because it roughly corresponds in our sample to the value required to reject at the $5 \%$ level of significance the null hypothesis that the population correlation coefficient is zero. ${ }^{11}$ Finally, the public

\footnotetext{
${ }^{10}$ Appendix B, Tables B1 to B16 provides detailed results for each country for all detrending methods for the full sample.

11 The cut-off point for the combined correlation in the case of combining independent correlation coefficient estimates, which is not strictly our case, would be slightly above 0.1 . Nevertheless, some studies recommend (see Rosenthal, 1991 ) to calculate the probabilities for combined correlations by combining the individual probability values of each correlation coefficient, in which case our cut-off point would be close to 0.3 . We take 0.2 as a compromise between the two alternatives which is in line with the cut-off values normally used in the literature.
} 
sector variable is said to be leading (lagging) the private sector variable if the maximum correlation coefficient is reached for negative (positive) values of $k$.

For nominal compensation per employee (Table 1) we find a dominant strong contemporaneous correlation for most countries of the sample and the euro area aggregate. The only exceptions are Spain, the Netherlands and Sweden, in which the dominant correlation is also strong and positive, but we find that private sector wage movements lead (precede) wage movements in the public sector. Belgium is the only case in which public sector wages lead private sector developments (moderate correlation). In most of the cases the results by method (see tables in Appendix B) tend to be in line with the dominant correlations according to the combined correlation. Even though there is some variation in the specific quantitative values, the qualitative message is quite robust.

The pattern of dominant contemporaneous correlations is also present when looking at the CCFs between variables in real terms. ${ }^{12}$ The size of the correlations is smaller, though. The euro area, Germany, France, Greece, Norway and Japan present a strong contemporaneous correlation, and Spain, Netherlands, Ireland, Portugal, Finland, Sweden and the United States present moderate or weak dominant correlations. Among big euro area countries Italy is an exception as it only shows a weak (lagged) positive correlation; nevertheless, this pattern is reversed when considering the sample 1980-2006. The difference between the correlations of nominal versus real variables is likely to be related to the fact that part of the correlation between nominal wages might be explained by price developments over the business cycle. At the same time, this evidence shows that public and private sector wages are correlated due to other factors than prices, most likely developments in productivity, institutional agreements or labour market linkages.

The annual (contemporaneous) correlation between public and private sector wages is a robust and generalised feature of our data. This is a very homogenous result in spite of very different institutional settings in the countries. It is worth noting that within the sample we have countries with highly unionised labour forces (like the Nordic countries) and countries with low unionisation like the US or Canada. A priori there would be no reason to expect that the observed patterns are the same for different countries given the important differences in institutions, organisation of the government sector and monetary policy. There would be no reasons either not to expect changes over time, given the different inflation regimes witnessed in the $60 \mathrm{~s}, 70 \mathrm{~s}, 80 \mathrm{~s}$ and $90 \mathrm{~s}$. Nevertheless, our findings appear quite robust both across countries and periods of time (1960-2006 and 1980-2006).

Interestingly, according to the relative standard deviations (public/private) shown in the first column of each panel, the cyclical components of public sector wages are more volatile than those of private sector wages for most countries (Table 1).

\footnotetext{
${ }^{12}$ For each country, and to obtain the most robust results, we averaged the (Fisher transformed) correlations of the 11 detrending methods using the two alternative deflators.
} 


\section{Medium- and long-run co-movements, and co-integration}

\section{1 den Haan's medium- and long-term co-movements}

In this section we analyse the co-movement between public and private sector wages using the correlation coefficients of forecast errors from vector autoregressive (VAR) systems at different forecast horizons, as proposed in den Haan (2000). This procedure adds two relevant features to the methods used in the previous section: (i) it is suited for the discussion of short-term, medium-, and long-term correlations; (ii) den Haan's procedure can be used for stationary as well as integrated series, so that no prior de-trending of the series is required. ${ }^{13}$

Figure 3 presents the correlations (with significance values) for nominal wages per employee and real wages per employee for the 1960-2006 sample for some selected euro area (euro area aggregate, Germany, France, Italy, Spain) and non-euro area countries (Sweden, US, UK, Canada, Japan). The whole set of results for all countries and both sample periods is presented in Appendix C in tables $\mathrm{C} 1$, $\mathrm{C} 2$ and $\mathrm{C} 3$.

As compared to the detrending methods presented in the previous section, den Haan's method focuses on the correlations between the irregular components, after having removed the trend and the inertia of the series, i.e. $T_{\mathrm{t}}+C_{\mathrm{t}}$. Correlations for $h=1$ would be directly comparable with the correlations for lag $k=0$ shown in Table 1 if the latter would be between irregular components instead of detrended series. When applying den Haan's method and thus filtering out the dynamics of the series due to the systematic autocorrelation $\left(C_{\mathrm{t}}\right)$, the co-movement patterns between public and private sector wages at horizon 1 are very similar than for the detrended series, with coefficients ranging from 0.4 to 0.8 for nominal wages, and from 0.4 to 0.7 for real wages. Figure 3 shows these correlations, which are the points vertically aligned at horizon 1 . In addition, these charts display the correlation of forecast errors at longer horizons, which gives an idea of medium term co-movements, being also positive correlated. Correlation coefficients between public and private sector wages tend to become larger when the forecast horizon increases, and then stabilise, typically at forecast horizons between 3 to 4 years.

Two countries are special. In line with the results for correlations between detrended wages, Italy shows a statistically insignificant correlation between real wages for the 1960-2006 sample, at all forecasting horizons. However, this pattern is reversed when looking at the 1980-2006 sample (see Table C1), in which case the results for Italy are in line with other big euro area economies. After removing the effect of prices, medium term correlations for Spain also lose significance, pointing to

\footnotetext{
${ }^{13}$ We run Den Haan's method assuming: (i) unit root in the variables, (ii) no unit root in the variables. For the sake brevity only the first set is shown, as the qualitative messages did not change by using (i) or (ii).
} 
the fact that medium-term co-movements might be led by price developments, rather than by other factors like productivity.

\subsection{Long-run relationship (co-integration)}

Co-integration reflects the long term relationship or long term co-movement among non-stationary variables, therefore this section focuses on long term co-movements rather than co-movements at the business cycle frequency, and thus can be seen as further evidence on long-run correlations on top of the one already presented in the previous section.

Wages (nominal and deflated) exhibit a single unit root as confirmed by several test under different specifications ${ }^{14}$ and thus we test for the presence of co-integrating relationships within a vector errorcorrection model (VEC henceforth). To determine the optimal number of lags we estimate an unrestricted vector autoregressive models (VAR) using the data in levels, and then choose the appropriate lag length using the Akaike, Schwarz and Hannan-Quinn information criteria. ${ }^{15}$ Then we rewrite the $\operatorname{VAR}(\mathrm{p})$ in error-correction form as a $\operatorname{VEC}(\mathrm{p}-1)$,

$\Delta y_{t}=\Pi \gamma_{t-1}+\sum_{s=1}^{p} \pi_{s} \Delta y_{t-s}+C h_{t}+\varepsilon_{t}$

where $y_{t}$ is a $k$ vector of non stationary I(1) variables. $\gamma_{t-1}$ includes $y_{t-1}$ and deterministic variables that enter the co-integration relation. $h_{t}$ is a vector of deterministic variables (constant and/or trend). Testing for co-integration between the non-stationary variables $y_{t}$ amounts to determining the rank of matrix $\Pi$. The standard strategy for determining the co-integrating rank is to test the sequence of null hypotheses, $\mathrm{H}_{0}: \operatorname{rank}(\Pi)=0, \mathrm{H}_{0}: \operatorname{rank}(\Pi)=1$. To test this sequence we use two standard Johansen tests: the Maximum eigenvalue and the Trace test (see, for example, Johansen, 1995).

Table 2 summarises the results of the standard Johansen tests for the most plausible VEC specifications. ${ }^{16} \mathrm{We}$ find that in most cases public and private sector nominal and real (deflated) wages are co-integrated, given that the null hypothesis $\mathrm{H}_{0}$ : $\operatorname{rank}(\Pi)=0$ is rejected in most cases and for most of the countries, while it is not the case for $\mathrm{H}_{0}$ : rank $(\Pi)=1$. Nominal wages in Norway and the UK are the only cases in which according to both co-integration tests $\mathrm{H}_{0}$ : rank $(\Pi)=0$ is not

\footnotetext{
${ }^{14}$ The existence of a second unit root is rejected in all cases, and we therefore safely assume that all series are I(1). Unit root test results are available from the authors upon request.

${ }^{15}$ When the outcomes of these criteria differ we take the smaller number of lags (p) that guarantees that the residuals of the VAR are normally distributed and do not present significant autocorrelation.

${ }^{16}$ The presence of deterministic components in the model affects the properties of the test for co-integration, therefore we tried all the possible different combinations of deterministic components in the data and/or the co-integrating equation. The selected specifications are available from the authors upon request.
} 
rejected at the 5\% level (though they are borderline cases). In the case of real variables, the only exceptions are the euro area aggregate, France, Belgium and Denmark when using the private consumption deflator (but not the GDP deflator); in the cases of France and Belgium the tests would signal that real wages are stationary.

\section{Who is in the driver seat?}

\subsection{Empirical specification}

One of the most common concepts of causality in empirical analyses is the one defined by Granger (1969). If a variable $x$ affects a variable $z$, the former should help improving the predictions of the later variable. A standard Granger-causality test can be implemented in a VAR framework.

In a first exercise we test for Ganger-causality for a stationary and stable process (detrended variables). In a second exercise we test Granger-causality between pairs of original variables (i.e. nondetrended). The restrictions characterising Granger-causality are exactly the same as in the stable case. Following Toda and Yamamoto (1995) and Dolado and Lütkephol (1996) we use a Wald test based on a lag augmented VAR. These authors show that a standard Wald test can be used to test linear constraints in this framework by just adding an extra lag in estimating the parameters of the process. This approach is quite appealing because the least-squared estimation may be applied to the levels of the $\operatorname{VAR}(\mathrm{p}+1)$ model. To carry out the causality test it is not necessary to perform a VEC reparameterisation of the process to account for cointegration, because the least-squares estimators of the relevant matrices do not change due to the reparameterisation.

The model we are interested in contains public sector wages, private sector wages and expected prices

$$
\left[\begin{array}{c}
w_{t}^{P U} \\
w_{t}^{P R} \\
E_{t}\left(p_{t+1}\right)
\end{array}\right]=C+\sum_{j=1}^{p} A_{j}\left[\begin{array}{c}
w_{t-j}^{P U} \\
w_{t-j}^{P R} \\
E_{t-j}\left(p_{t-j-1}\right)
\end{array}\right]+\varepsilon_{t}
$$

where $C$ is a $3 \times 1$ vector of constant coefficients, each $A_{j}$ is a $3 \times 3$ matrix, $p$ the order of the VAR, and $\varepsilon$ a $3 \times 1$ vector of random disturbances. $w_{t}^{P U}$ denotes nominal wages in the public sector, $w_{t}^{P R}$ nominal wages in the private sector, and $E_{t}\left(p_{t+1}\right)$ the expected price level in $\mathrm{t}+1$. If expected prices at time $\mathrm{t}$ are proxied by actual prices, the corresponding equations for public and private sector wages turn out to be

$$
\begin{aligned}
& w_{t}^{P U}=C_{1}+a_{0}^{P U} p_{t}+a_{1}^{P U} p_{t-1}+\cdots+a_{p}^{P U} p_{t-p}+A_{P U}^{1}(L) w_{t}^{P U}+A_{P R}^{1}(L) w_{t}^{P R}+\varepsilon_{t}^{P U} \\
& w_{t}^{P R}=C_{2}+a_{0}^{P R} p_{t}+a_{1}^{P R} p_{t-1}+\cdots+a_{p}^{P R} p_{t-p}+A_{P U}^{2}(L) w_{t}^{P U}+A_{P R}^{2}(L) w_{t}^{P R}+\varepsilon_{t}^{P R}
\end{aligned}
$$


Within this formulation we can accommodate our previous discussion on nominal and real wages. In order to make a general discussion of the impact of prices on the relationship between wages in both sectors, we look at the results of two comparable sets of estimated equations:

(i) [Nominal wages] Impose in (3) and (4) the constraints $a_{0}^{i}=a_{1}^{i}=\cdots=a_{p}^{i}=0$, for $i=P U, P R$.

(ii) [Nominal wages and prices] Equations (3) and (4) without constraints on the coefficients.

Notice that in the standard practice real wages are defined in such a way that $a_{0}^{i}=1$. Imposing this constraint and rearranging the resulting coefficients to express all wage variables in, say, equation (3), as real (deflated) wages (i.e. $w_{t}^{P U}-p_{t}$ ), the following particular case of equation (3) can be obtained: $w_{t}^{P U}-p_{t}=C_{1}+A_{P U}^{1^{*}}(L)\left(w_{t}^{P U}-p_{t}\right)+A_{P R}^{1^{*}}(L)\left(w_{t}^{P R}-p_{t}\right)+A^{*}(L) p_{t}+\varepsilon_{t}^{P U}$. If, in addition, the constraint $A^{*}(L)=0$ is imposed, thus restricting the VAR to include only real (deflated) public and private wages), the previous equation turns out to be $w_{t}^{P U}-p_{t}=C_{1}+A_{P U}^{1^{*}}(L)\left(w_{t}^{P U}-p_{t}\right)+$ $A_{P R}^{1^{*}}(L)\left(w_{t}^{P R}-p_{t}\right)+\varepsilon_{t}^{P U}$. This specification is a quite restricted formulation of equation (3), and the equivalent equation (4), and thus we preferred to contemplate the two, more general cases (i) and (ii) above as a parallel to the exercise carried out in the previous sections with nominal and real (deflated) variables.

\subsection{Causality analysis}

Table 3 shows the results of the first exercise analysing causality. It summarises the results of running Granger-Causality tests with VAR models with nominal compensation per employee in the public and private sector (exercise (i) above), and the same vector but including expected prices (exercise (ii) above). For each 2-variables or 3-variables specification we detrended the variables using the 11 detrending methods described in a previous section (first differences being one, and the other ten shown under "Other filters"), and then we run the corresponding Granger-causality tests for each group. We show an arrow when at least 6 methods out of 11 showed significant evidence of Grangercausality. ${ }^{17}$

For nominal wages (first two columns of Table 3), the dominant pattern is one in which private sector developments over the business cycle cause public sector developments. This is correct for the euro area aggregate and most member countries in the sample: Germany, France, Italy, Spain, Netherlands, Greece, Portugal and Finland. Finland, Sweden and Denmark show bi-directional causality, whereby past developments in private sector wages do have an influence on public sector today but also past

${ }^{17}$ Results for $1980-2006$ can be found in Appendix D, Table D1. 
public sector wages do contain valuable information to predict today's private wages. In the AngloSaxon group the US, the UK and Canada show causality from the private to the public sector, while in Belgium and Japan the causality flows in the opposite direction (from public to private).

When prices are taken explicitly into account in the VAR (columns 3 onwards in Table 3 ) some leading behaviour from public to private sector wages arises in the case of Ireland, France, Finland and Italy (in the latter case weak evidence: 5 out of 11 methods) and Germany and Belgium only when applying the private consumption deflator. A remarkable result is that the dominant leading behaviour of the private sector wages vanishes for the Anglo-Saxon countries as well as for Italy, Spain, Greece and Portugal. In general comparing results for bi-variate nominal wage VARs with those when prices are taken into account it seems that prices are likely to play an important role in the transmission of private wage leadership.

Table 4 presents the results of the second exercise carried out to analyze causality. It shows Grangercausality results using VARs in the levels of the variables. In this section causality results do not only show linkages over business cycle frequencies, but rather have to be interpreted as a mixture of shortand long-run linkages. ${ }^{18}$ As regards nominal wages (columns 1 and 2, Table 4) there is again broad evidence in favour of private sector wages leading public sector wages; this is found for all countries except Netherlands, Ireland and Norway. There are a number of instances in which nominal wages in the public sector do have some explanatory power for future private sector nominal wages: Italy, Netherlands, Greece, Portugal and, in line with the results for the VARs with detrended variables, also Finland, Sweden and Denmark.

There are quite a few instances of Granger-causality from private to public wages when the VARs are extended to account for expected inflation (columns 3 to 6). In line with the earlier analysis, Ireland, France, Finland and the Netherlands (and Italy for GDP deflator only) also show Granger causality from public to private wages for both inflation measures. Again, it is remarkable that the evidence on Granger causality from private to public nominal wages fades away for some countries and the euro area once price development are accounted for. Results from both causality exercises in table 3 and 4 therefore suggest that prices are a relevant factor behind the private wage leadership. The results from the VARs described above allow us to look at the interaction between public and private sector wages and prices, which nevertheless would deserve an even deeper investigation.

Table 5 complements table 4 by showing the causality links between prices and wages when the VARs are extended to account for expected inflation. Prices Granger cause private wages. ${ }^{19}$ Prices also affect public wages in most countries although the evidence is weaker in a few cases (Austria, Greece,

\footnotetext{
${ }^{18}$ Detailed results of running these tests with different specifications and p-values for the relevant null hypothesis are presented in Appendix E (Tables E1, E2 and E3).

${ }^{19}$ With the only exception of Belgium which is somewhat surprising given institutionalised wage indexation in this country. In any case, the results for Belgium have to be taken with care given some observed outliers in the dataset used for this country.
} 
Portugal, Finland) where only one of the deflators shows significant results. When looking at causality from wages to prices, private wage increases help explain future price increases. The only clear exceptions are the Anglo-Saxon countries. As regards public wages, in the case of Spain, Netherlands and Finland they seem to feed back to prices with both deflators. For the rest of the countries in our sample the evidence on public wages causing prices is mixed and depends on the deflator. Again there is no feedback in the case of the Anglo-Saxon countries.

Overall, there are significant indirect influences from private wages on the price level which we find for all countries plus the euro area aggregate (Column 3). While this influence can also be found for public wages, the evidence is in many cases weaker and depends on the deflator. Price level changes are found to affect private and (in somewhat fewer cases) public wages. Second round effects therefore could play an important role on wage and prices dynamics in EU countries and the euro area (although a deeper analysis to confirm this finding is warranted).

\subsection{Public wage leadership and wage setting institutions}

Contrary to the robust results that we get for the co-movement of public and private sector wages, our causality results show a large degree of country heterogeneity. Thus, in this section we try to answer the following question: is there any relationship between empirical findings on public wage leadership and institutional features of labour and product markets, notably wage setting institutions, across countries?

We examine the role of institutional features in raising the probability of public sector wage leadership (i.e. granger-causality from public to private wages) with the help of a Probit analysis. In those instances where public sector wage leadership was statistically significant, i.e. public sector wages caused private sector wages, our dependent variable takes the value of 1 (183 observations), otherwise it is set as zero (249 observations). Observations are derived from the findings on wage leadership that includes 12 methods (11 detrending methods and VARs in levels) and 2 deflators for the 18 industrial countries in our sample (which yields up to 432 observations). Independent variables include a set of standard OECD-based variables of labour and product market institutions, a set of variables on wage bargaining institutions in Europe, the US and Japan generated from the information collected within the European System of Central Banks Wage Dynamics Network (WDN), ${ }^{20}$ and a measure of globalisation (see Appendix F for details and sources). The fact that the OECD data base is not available for Greece and the WDN-based institutional data is not available for Canada and Norway reduces the maximum number of observations from 432 to 360 .

As regards variables available from the OECD-based data set, we formulate some testable hypotheses on the expected impact of labour market institutions on public wage leadership: (i) stronger

\footnotetext{
${ }^{20}$ Based on a standardised questionnaire answered by national experts from central banks of each one of the 22 countries considered, for 2 years (1995 and 2006) (see Du Caju et al., 2008).
} 
bargaining coordination between negotiating parties (being state-sponsored and state-imposed coordination one defining feature) and higher union membership may suggest a strong role for a wage negotiation benchmark and this may most easily be in the public sector due to the higher degree of unionisation; (ii) the impact of bargaining centralisation is less clear; on the one hand the same arguments as for bargaining coordination apply while, on the other hand, centralisation may be conducive to internalise more of the external effects of wage setting across all negotiating parties (hence, less public wage leadership); (iii) stricter employment protection legislation gives unions a stronger bargaining power in the private sector, independent of public sector outcomes and, hence, one might expect a weaker influence of public wages.

The variables on wage setting institutions collected via the WDN suggest the following hypotheses: (i) the degree of government involvement in collective bargaining is likely to be positively correlated with a public wage leadership role; (ii) a higher degree of price indexation is less likely to be positively correlated with public than with private sector wage leadership, as private wages, by comprising about $80 \%$ of countries' wage bill, are a key driver of inflation. This, in turn, determines the next round of wages increases (wage price spiral); (iii) a prevalence of occupational and company-level wage setting is likely to focus negotiations on the specific (private) occupation or firm situation and, hence, less likely to coincide with a strong lead role for the public sector; (iv) more regional wage setting (coupled with social safety nets and inter-regional redistribution more or less prevalent in all industrialised countries) may allow more of a public sector lead role as regions can externalise at least part of the costs (with, e.g., higher unemployment "automatically" leading to more transfers).

As to other control variables, we hypothesise that: (i) stronger exposure to global competition constraints (index of globalisation) limits the lead role of the public sector in wage setting; (ii) stronger exposure to competition pressures in the domestic product markets also limits the leadership of public wages as market constraints are more binding and firms have less scope to accommodate other influences (product market regulation index). Or, arguing the other way round, stronger product market regulation facilitates public sector leadership. A measure of the public sector size (public employment rate) which is likely to be positively correlated with a higher probability of public wage leadership is also included in the regression.

The findings as reported in Table 6 largely confirm these hypotheses. ${ }^{21}$ Column 1 illustrates the positive correlation between public wage leadership on the one hand and co-ordinated wage bargaining, government involvement, union membership and product market regulation on the other.

A high globalisation index, wage indexation and employment protection show a negative sign of the respective coefficients. When including additional WDN variables (column 2), the expected negative

${ }^{21}$ The estimated coefficients shown in this table yield the marginal effect of a change in independent variables on the probability of public wage causation. The estimations include method dummies and deflator dummies in columns 1 and 2 . However, they do not include country dummies, given that these would capture the cross country institutional variation which we want to be reflected in the explanatory variables. 
correlation between occupational and company-level wage bargaining and public wages causing private wages becomes visible. Predominant wage bargaining at the regional level coincides with public wage leadership as expected though somewhat less robustly. With the inclusion of these variables, bargaining coordination (unsurprisingly) loses significance and so does globalisation as there is likely to be multicollinearity. The share of public employment turns to have a significant and positive coefficient as expected; also unsurprisingly, government involvement loses significance when the share of public employment is introduced in the regressions (column 3). Columns 4 and 5 illustrate that the findings are robust across the two deflators of wages (GDP deflator and private consumption deflator).

\section{Conclusions}

The paper provides, firstly, empirical evidence on the correlation of public and private wages over the business cycle. The study finds that in the euro area and most of the countries of our sample private wages are positively and strongly correlated with public wages over the business cycle mostly contemporaneously. Our findings appear quite robust both across countries and periods (1960-2006 and 1980-2006).

Secondly, the paper finds short- medium and long-run co-movements between public and private sector wages. For the short-run correlations, the results of the previous (robust) analysis are confirmed. For the co-movements at longer frequencies than the standard business cycle, our results show a strong correlation between public and private sector wages. Thirdly, (and unsurprisingly) the paper reports the existence of a long-run relationship between public and private sector wages in all the countries of the analysed sample. Wages in both sectors share a common driving trend that can be interpreted as a combination of long-run trends in prices and aggregate productivity.

Fourthly, the paper conducts a thorough analysis of causality. We run Granger-causality tests for different transformations of the nominal and deflated wage variables. First, we look at VARs between detrended variables (using eleven detrending methods), and thus focus on the Granger-causal links over the business cycle. We find a dominant pattern of private sector wage leadership over the business cycle for nominal wages and a few cases of bi-directional causality. When prices are explicitly taken into account, the dominant private sector lead vanishes, suggesting that the price level is an important adjustment parameter. Moreover, some leading behaviour from the public to the private sector arises. In a second exercise, we run VARs in levels (logs) of the variables which broadly confirm the findings of the first approach. A first look at the role of prices seem to indicate that there are significant feedback effects from private wages on the price level which we find for all countries plus the euro area aggregate. While this influence can also be found for public wages, the evidence is in many cases weaker and depends on the deflator. 
Finally, we examine labour and product market institutional features in relation to the results found on public sector wage leadership. Factors that are conducive to public wage leadership include strong bargaining coordination with government involvement in collective bargaining, strong product market regulation, a high ratio of union membership in employment, and regional wage bargaining. Factors that appear to have a negative relationship with public wage leadership include decentralised bargaining at the company or occupational level, strong employment protection legislation, a high globalisation index (less robust), and a high coverage of wage setting by inflation indexation mechanisms.

From a policy perspective, we can conclude: public and private wages do not decouple. Private sector wages seem to exert mostly a stronger influence on public wages than the other way round. However, on the whole and in a number of countries results of correlation and causality analysis also suggest an important influence from the public sector on private wages both directly and indirectly via prices. This has important policy implications in that private but also public wage setting are important for overall wage and competitiveness developments. Moreover, second round effects seem to play an important role in wage and prices dynamics.

In the light of the obtained results, some follow-up work is warranted to further improve the understanding of the subject matter of this paper. First, the concept of Granger-causality captures the idea of the predictive power that past values of a given variable do have when forecasting another variable. Thus, given the annual frequency used for the data we cannot analyse empirically the intraannual causal links, i.e. which sector leads within the current year. This might be a potentially relevant issue if indeed there were to be intra-year linkages between wages in the public and the private sector. These could operate irrespective of the fact that nominal wage contracts are typically fixed for a year, i.e. a 4-quarter period, or even for longer time periods by reflecting staggered sectoral wage negotiations or discretionary within-the-year wage increases (bonuses, promotions etc). Second, with EMU or perhaps already with the signing of the Maastricht Treaty public and private wage interaction may have adjusted in the euro area. Empirical analysis that wants to address these two caveats would have to overcome the data shortcoming that has induced us to conduct the analysis with annual data.

\section{References}

Abraham, K. and J.C. Haltiwanger (1995), "Real wages and the Business Cycle", Journal of Economic Literature 33, pp. 1215-1264.

Agénor, P.-R. (1995), “The labor market and economic adjustment”, IMF WP 95/125, Washington D.C.

Alesina, A., S. Ardagna, R. Perotti and F. Schiantarelli (2002), "Fiscal policy, profits and investment", American Economic review 92, pp. 571-589. 
Alesina, A., R. Baquir and W. Easterly (2000), "Redistributive public employment", Journal of Urban Economics 48, pp. 219-241.

Alesina, A., S. Danninger and M. Rostagno (2001), "Redistribution through pubic employment: the case of Italy”, IMF Staff Papers 48, pp. 447-473.

Afonso, A. and P. Gomes (2008), "Some Determinants of Public and Private Sector Wages", Mimeo: ECB.

Algan, Y., P. Cahuc and A. Zylberberg (2002), "Public employment: does it increase unemployment?", Economic Policy, pp. 9-65.

Allard, G. (2005), “Measuring Job Security Over Time: In Search of a Historical Indicator”, Instituto de Empresa Working Paper WP-05. (http://www.ie.edu/eng/claustro/claustro_working_papers.asp).

Ardagna, S. (2007), "Fiscal policy in unionized labor markets", Journal of Economic Dynamics and Control 31, pp. 1498-1534.

Bemmels, B. G. and M. A. Zaidi (1990), "Wage leadership in Canadian industry", Applied Economics 22, pp. 553-567.

Demekas, D. G. and Z. G. Kontolemis (2000), "Government Employment and Wages and Labour Market Performance", Oxford Bulletin of Economics and Statistics 62, pp. 391-415..

Calmfors, L. and H. Horn (1986), "Employment policies and centralized wage setting", Economica 53, pp. 281-302.

Camacho, M., G. Pérez-Quirós and L. Saiz (2006), "Are European business cycles close enough to be just one?", Journal of Economic Dynamics and Control 30, pp. 1687-1706.

Christiano L.J. and T.J. Fitzgerald (2003), "The Band Pass Filter", International Economic Review 44, pp. $435-465$.

Christou, C., A. Klemm and A. Tiffin (2007), "Wage Dynamics in the Romanian Economy", IMF Article IV, Selected Issues, pp. 34-50.

Conway, P., V. Janod and G. Nicoletti (2005), "Product Market Regulation in OECD countries, 1998 to 2003", OECD Economics Department Working Paper, No. 419.

David, F. (1949), "The moments of the $\mathrm{z}$ and F distributions", Biometrika 36, pp. 394-403.

den Haan, W. (2000), "The Co-movement Between Output And Prices", Journal of Monetary Economics 46, pp. 3-30.

Dolado, J.J. and H. Lütkeppohl (1996). "Making Wald test work for cointegrated VAR systems" Econometric Reviews 15: 369-386.

Dreher, A. (2008), "Measuring Globalisation - Gauging its Consequence”, New York: Springer.

Du Caju, P., E. Gautier, D. Momferatou, and M. Ward-Warmedinger (2008), “Institutional Features of Wage Bargaining in 22 EU countries, the US and Japan”, Frankfurt am Main: Mimeo. 
Forni, L. and R. Giordano (2003), "Employment in the public sector", CESIFO Working Paper n. 1085.

Friberg, K. (2007), "Intersectoral Wage linkages: the case of Sweden”, Empirical Economics 32, pp. $161-184$

Gelb, A., J. B. Knight and R. H. Sabot (1994), "Public sector employment, rent seeking and economic growth", Economic Journal 101, pp. 1186-1199.

Granger, C. W. J. (1969), "Investigating casual relations by econometric models and cross-spectral methods", Econometrica 37, pp. 424-438.

Granger, C. W. J. and Y. Jeon (2004), “Thick Modeling”, Economic Modelling 21, pp. 323-343.

Gregory, R. G. and J. Borland (1999), "Recent developments in public sector labor markets", in O. Ashenfelter and D. Card (eds.), Handbook of Labor Economics vol. III, Elsevier, Netherlands.

Gylfason, T. and A. Lindbeck (1984), "Union rivalry and wages. An oligopolistic approach", Eocnomica 51, pp. 129-139.

Harvey, A. (1989), Structural Time Series Models and the Kalman Filter, Cambridge University Press, Cambridge, UK.

Holmlund, B. (1993), "Wage setting in private and public sectors in a model with endogenous government behaviour", European Journal of Political Economy 9, pp. 149-62.

Holmlund, B. and H. Ohlson (1992), "Wage linkages between private and public sectors in Sweden", Labour 6, pp. 3-17.

Jacobson, T. and H. Ohlsson (1994), "Long run relations between private and public sector wages in Sweden", Empirical Economics 19, pp. 343-360.

Johansen, S. (1995), "Likelihood-Based Inference in Cointegrated Vector Autoregressive Models". Oxford: Oxford University Press.

Lamo, A., J. J. Pérez and L. Schuknecht (2007), "The cyclicality of consumption, wages and employment of the public sector in the euro area”, European Central Bank Working Paper 757.

Lindquist, M. J. and R. Vilhelmsson (2004), “Is the Swedish Central Government a Wage Leader?", Working Paper 8/2004 Swedish Institute for Social Research, Stockholm University.

Matschke, X. (2003), “Are there election cycles in wage agreements? An analysis of German public employees", Public Choice 114, pp. 103-135.

Mizala, A. and P. Romaguera (1995), "Testing for wage leadership processes in the Chilean economy", Applied Economics 27, 303-310.

Nunziata, L. (2005), "Institutions and Wage Determination: a Multi-country Approach", Oxford Bulletin of Economics and Statistics 67, 4, pp. 435-465.

Ochel , W. (2000), "Collective bargaining (centralisation/coordination)”, Munich: IFO Institute. 
OECD (1997), "Measuring public employment in OECD countries: sources, methods and results", Paris.

Osterwald-Lenum, M. (1992), "A note with quantiles of the asymptotic distribution of the maximum likelihood cointegration rank test statistics". Oxford Bulletin of Economics and Statistics 54, pp. 461-472.

Pedersen, P. J., J. B. Schmidt-Sorensen, N. Smith, and N. Westegard-Nielsen (1990), "Wage differentials between the public an private sectors", Journal of Public Economics 41, pp. 125-145.

Quadrini, V. and A. Trigari (2007), "Public employment and the business cycle", Scandinavian Journal of Economics 109, pp. 723-742.

Rodrick, D. (2000), "What drives public employment in developing countries?", Review of Development Economics 4, pp. 229-243.

Rosenthal, R. (1991), Meta-analytic procedures for social research. Sage Publications Inc., Newbury Park, CA (USA).

Strom, B. (1997), "Envy, fairness and political influence in local government wage determination: evidence from Norway", Economica 62, pp. 389-409.

Tagtstrom, S. (2000), "The wage spread between different sectors in Sweden", Sveriges Riskbank Economic Review 4, pp. 77-82.

Toda, H. Y. and T. Yamamoto (1995), "Statistical inference in vector autoregressions with possibly integrated processes", Journal of Econometrics 66, pp. 225-250.

Visser, J. (2006), “Union Membership Statistics in 24 Countries”, Monthly Labour Review, January, pp. 38-49.

Young, P. C., D. Pedregal, and W. Tych (1999), "Dynamic Harmonic Regression", Journal of Forecasting 18, pp. 369-394. 
Table 1. The correlations of detrended public and private wages per employee. Combinations of

Fisher transformations. Annual data 1960-2006 and 1980-2006.

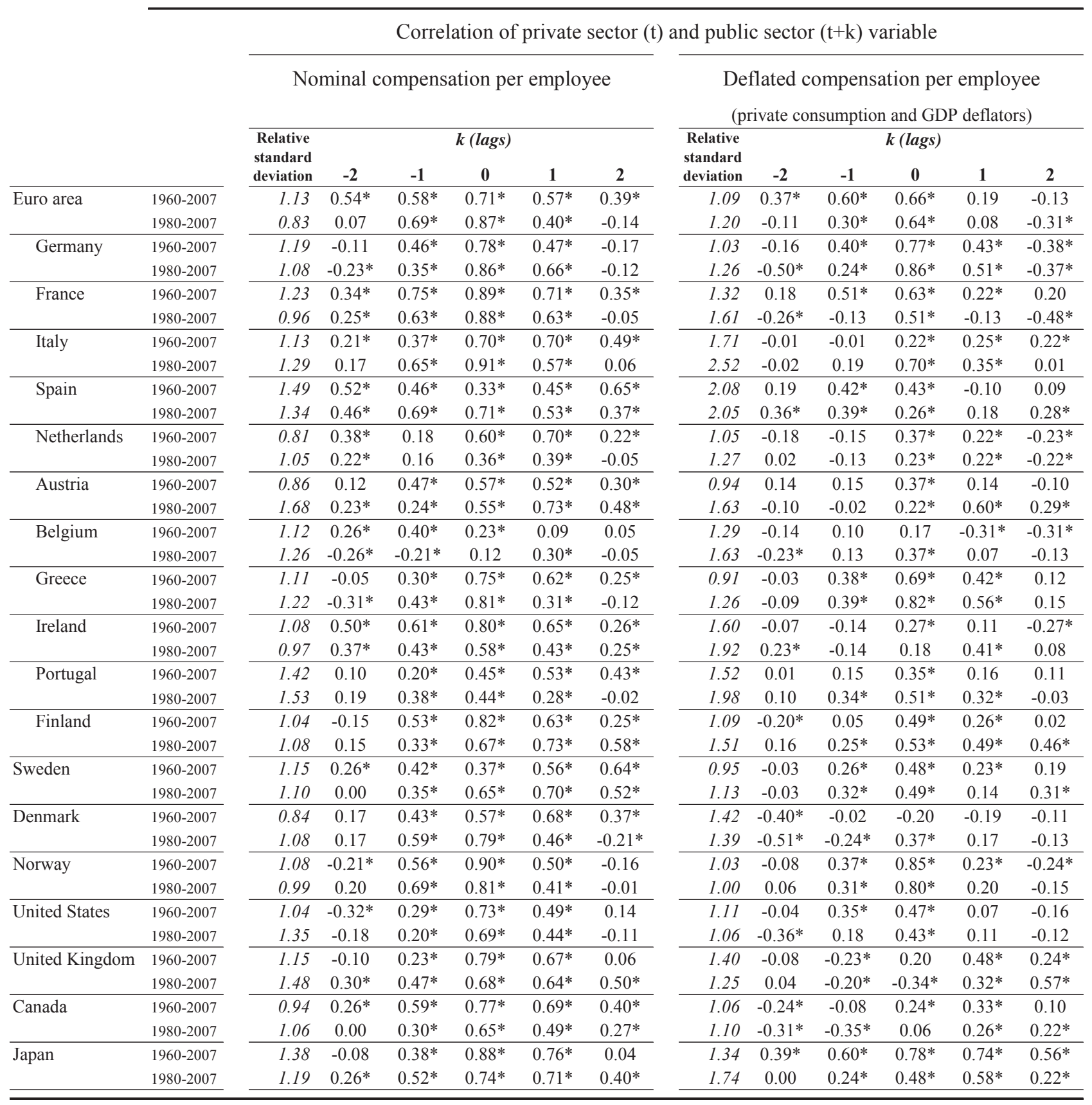

Note: an asterisk indicates significance at the $5 \%$ level. 
Table 2. Cointegration tests: Johansen approach. Annual data 1960-2006.

\begin{tabular}{|c|c|c|c|c|c|c|c|c|c|c|c|c|c|}
\hline & \multirow[b]{3}{*}{$\begin{array}{r}\text { Max } \\
\text { Rank } \\
\end{array}$} & \multirow{2}{*}{\multicolumn{4}{|c|}{$\begin{array}{l}\text { Nominal compensation } \\
\text { per employee }\end{array}$}} & \multicolumn{8}{|c|}{$\begin{array}{l}\text { Deflated compensation per employee } \\
\quad(\text { deflated = nominal / price level })\end{array}$} \\
\hline & & & & & & \multicolumn{4}{|c|}{ Private consumption deflator } & \multicolumn{4}{|c|}{ GDP deflator } \\
\hline & & $\begin{array}{c}\text { Max } \\
\text { Statistic } \\
\end{array}$ & $\begin{array}{l}\text { Critical } \\
\text { Values } \\
\end{array}$ & $\begin{array}{c}\text { Trace } \\
\text { Statistic } \\
\end{array}$ & $\begin{array}{l}\text { Critical } \\
\text { Values } \\
\end{array}$ & $\begin{array}{c}\text { Max } \\
\text { Statistic } \\
\end{array}$ & $\begin{array}{l}\text { Critical } \\
\text { Values } \\
\end{array}$ & $\begin{array}{c}\text { Trace } \\
\text { Statistic } \\
\end{array}$ & $\begin{array}{l}\text { Critical } \\
\text { Values } \\
\end{array}$ & $\begin{array}{c}\text { Max } \\
\text { Statistic } \\
\end{array}$ & $\begin{array}{l}\text { Critical } \\
\text { Values } \\
\end{array}$ & $\begin{array}{c}\text { Trace } \\
\text { Statistic } \\
\end{array}$ & $\begin{array}{l}\text { Critical } \\
\text { Values } \\
\end{array}$ \\
\hline \multirow[t]{2}{*}{ Euro area } & $\mathbf{0}$ & $28.0 *$ & 19.0 & $33.3^{*}$ & 25.3 & 13.1 & 19.0 & 21.0 & 25.3 & $20.5 *$ & 19.0 & $32.7^{*}$ & 25.3 \\
\hline & 1 & 5.2 & 12.5 & 5.2 & 12.3 & 7.9 & 12.5 & 7.9 & 12.3 & 12.1 & 12.5 & 12.1 & 12.3 \\
\hline \multirow[t]{2}{*}{ Germany } & $\mathbf{0}$ & $20.6^{*}$ & 19.0 & 25.0 & 25.3 & 13.9 & 14.1 & $16.2 *$ & 15.4 & $18.1^{*}$ & 15.7 & $23.9 *$ & 20.0 \\
\hline & 1 & 4.4 & 12.5 & 4.4 & 12.3 & 2.3 & 3.8 & 2.3 & 3.8 & 5.9 & 9.2 & 5.9 & 9.4 \\
\hline \multirow[t]{2}{*}{ France } & $\mathbf{0}$ & 15.5 & 15.7 & $20.4 *$ & 20.0 & $24.0^{*}$ & 14.1 & $29.0^{*}$ & 15.4 & $46.7^{*}$ & 15.7 & $51.5^{*}$ & 20.0 \\
\hline & 1 & 4.9 & 9.2 & 4.9 & 9.4 & $4.9 *$ & 3.8 & $4.9^{*}$ & 3.8 & 4.8 & 9.2 & 4.8 & 9.4 \\
\hline \multirow[t]{2}{*}{ Italy } & $\mathbf{0}$ & $24.7^{*}$ & 19.0 & $29.7 *$ & 25.3 & $27.1 *$ & 15.7 & $29.5^{*}$ & 20.0 & $21.0^{*}$ & 19.0 & $32.6^{*}$ & 25.3 \\
\hline & 1 & 5.0 & 12.5 & 5.0 & 12.3 & 2.4 & 9.2 & 2.4 & 9.4 & 11.6 & 12.5 & 11.6 & 12.3 \\
\hline \multirow[t]{2}{*}{ Spain } & $\mathbf{0}$ & $17.3 *$ & 15.7 & $22.8^{*}$ & 20.0 & $21.8 *$ & 16.9 & $25.4^{*}$ & 18.2 & $23.0 *$ & 11.4 & $23.4 *$ & 12.5 \\
\hline & 1 & 5.5 & 9.2 & 5.5 & 9.4 & 3.6 & 3.7 & 3.6 & 3.7 & 0.3 & 3.8 & 0.3 & 3.8 \\
\hline \multirow[t]{2}{*}{ Netherlands } & $\mathbf{0}$ & $19.3^{*}$ & 15.7 & $21.2 *$ & 20.0 & $20.3^{*}$ & 15.7 & $27.0^{*}$ & 20.0 & 12.6 & 14.1 & $16.1 *$ & 15.4 \\
\hline & 1 & 1.9 & 9.2 & 1.9 & 9.4 & 6.7 & 9.2 & 6.7 & 9.4 & 3.5 & 3.8 & 3.5 & 3.8 \\
\hline \multirow[t]{2}{*}{ Austria } & $\mathbf{0}$ & $18.9^{*}$ & 15.7 & $27.3^{*}$ & 20.0 & $22.7^{*}$ & 15.7 & $29.3 *$ & 20.0 & $22.2^{*}$ & 15.7 & $28.1 *$ & 20.0 \\
\hline & 1 & 8.3 & 9.2 & 8.3 & 9.4 & 6.6 & 9.2 & 6.6 & 9.4 & 5.9 & 9.2 & 5.9 & 9.4 \\
\hline \multirow[t]{2}{*}{ Belgium } & $\mathbf{0}$ & $20.8^{*}$ & 14.1 & $23.6^{*}$ & 15.4 & $22.8^{*}$ & 19.0 & $36.6^{*}$ & 25.3 & $20.9 *$ & 14.1 & $24.2 *$ & 15.4 \\
\hline & 1 & 2.8 & 3.8 & 2.8 & 3.8 & $13.8^{*}$ & 12.5 & $13.8 *$ & 12.3 & 3.3 & 3.8 & 3.3 & 3.8 \\
\hline \multirow[t]{2}{*}{ Greece } & $\mathbf{0}$ & 16.6 & 19.0 & $26.9 *$ & 25.3 & $19.5^{*}$ & 15.7 & $21.9 *$ & 20.0 & $19.3^{*}$ & 15.7 & $21.1 *$ & 20.0 \\
\hline & 1 & 10.3 & 12.5 & 10.3 & 12.3 & 2.4 & 9.2 & 2.4 & 9.4 & 1.7 & 9.2 & 1.7 & 9.4 \\
\hline \multirow[t]{2}{*}{ Ireland } & 0 & $25.2 *$ & 19.0 & $36.3^{*}$ & 25.3 & $34.0 *$ & 15.7 & $40.7^{*}$ & 20.0 & $25.8^{*}$ & 15.7 & $33.4^{*}$ & 20.0 \\
\hline & 1 & 11.1 & 12.5 & 11.1 & 12.3 & 6.7 & 9.2 & 6.7 & 9.4 & 7.6 & 9.2 & 7.6 & 9.4 \\
\hline \multirow[t]{2}{*}{ Portugal } & $\mathbf{0}$ & $16.6^{*}$ & 15.7 & $23.4 *$ & 20.0 & $23.3^{*}$ & 15.7 & $28.2^{*}$ & 20.0 & $26.2^{*}$ & 15.7 & $28.5^{*}$ & 20.0 \\
\hline & 1 & 6.7 & 9.2 & 6.7 & 9.4 & 4.9 & 9.2 & 4.9 & 9.4 & 2.3 & 9.2 & 2.3 & 9.4 \\
\hline \multirow[t]{2}{*}{ Finland } & $\mathbf{0}$ & $23.4 *$ & 15.7 & $28.3^{*}$ & 20.0 & $19.5^{*}$ & 15.7 & $22.9 *$ & 20.0 & $21.1 *$ & 15.7 & $24.2 *$ & 20.0 \\
\hline & 1 & 4.9 & 9.2 & 4.9 & 9.4 & 3.4 & 9.2 & 3.4 & 9.4 & 3.1 & 9.2 & 3.1 & 9.4 \\
\hline \multirow[t]{2}{*}{ Sweden } & $\mathbf{0}$ & $23.9 *$ & 16.9 & $24.8 *$ & 18.2 & $12.2 *$ & 11.4 & $14.3 *$ & 12.5 & $30.9 *$ & 15.7 & $35.9 *$ & 20.0 \\
\hline & 1 & 0.9 & 3.7 & 0.9 & 3.7 & 2.2 & 3.8 & 2.2 & 3.8 & 5.0 & 9.2 & 5.0 & 9.4 \\
\hline \multirow[t]{2}{*}{ Denmark } & $\mathbf{0}$ & $25.9^{*}$ & 15.7 & $29.7 *$ & 20.0 & $19.6^{*}$ & 15.7 & $19.4 *$ & 18.2 & $32.0 *$ & 15.7 & $41.2 *$ & 20.0 \\
\hline & 1 & 3.8 & 9.2 & 3.8 & 9.4 & 7.7 & 9.2 & $4.0^{*}$ & 3.7 & 9.2 & 9.2 & 9.2 & 9.4 \\
\hline \multirow[t]{2}{*}{ Norway } & $\mathbf{0}$ & 12.4 & 15.7 & 17.1 & 20.0 & $21.9^{*}$ & 19.0 & $27.8^{*}$ & 25.3 & $17.0 *$ & 15.7 & $23.7^{*}$ & 20.0 \\
\hline & 1 & 4.7 & 9.2 & 4.7 & 9.4 & 5.8 & 12.5 & 5.8 & 12.3 & 6.7 & 9.2 & 6.7 & 9.4 \\
\hline \multirow[t]{2}{*}{ United States } & $\mathbf{0}$ & 13.9 & 15.7 & $22.1 *$ & 20.0 & 12.9 & 15.7 & $20.4 *$ & 20.0 & $19.5^{*}$ & 15.7 & $28.1 *$ & 20.0 \\
\hline & 1 & 8.3 & 9.2 & 8.3 & 9.4 & 7.5 & 9.2 & 7.5 & 9.4 & 8.6 & 9.2 & 8.6 & 9.4 \\
\hline \multirow[t]{2}{*}{ United Kingdom } & $\mathbf{0}$ & 10.6 & 15.7 & 19.2 & 20.0 & $26.3^{*}$ & 15.7 & $33.6^{*}$ & 20.0 & $23.3^{*}$ & 15.7 & $27.7 *$ & 20.0 \\
\hline & 1 & 8.5 & 9.2 & 8.5 & 9.4 & 7.3 & 9.2 & 7.3 & 9.4 & 4.4 & 9.2 & 4.4 & 9.4 \\
\hline Canada & 0 & 13.6 & 15.7 & $21.7^{*}$ & 20.0 & $25.8^{*}$ & 19.0 & $29.7 *$ & 25.3 & $17.5^{*}$ & 15.7 & $25.3^{*}$ & 20.0 \\
\hline & 1 & 8.1 & 9.2 & 8.1 & 9.4 & 3.9 & 12.5 & 3.9 & 12.3 & 7.8 & 9.2 & 7.8 & 9.4 \\
\hline Japan & $\mathbf{0}$ & $21.9 *$ & 19.0 & $30.7 *$ & 25.3 & 17.9 & 19.0 & $28.4 *$ & 25.3 & 15.6 & 19.0 & $26.4 *$ & 25.3 \\
\hline & 1 & 8.8 & 12.5 & 8.8 & 12.3 & 10.5 & 12.5 & 10.5 & 12.3 & 10.8 & 12.5 & 10.8 & 12.3 \\
\hline
\end{tabular}

Note: an asterisk indicates significance at the $5 \%$ level. Osterwald-Lenum critical values for both the Maximum-eigenvalue and Trace test statistics. 
Table 3. Granger Causality tests I: detrended variables. Annual data 1960-2006.

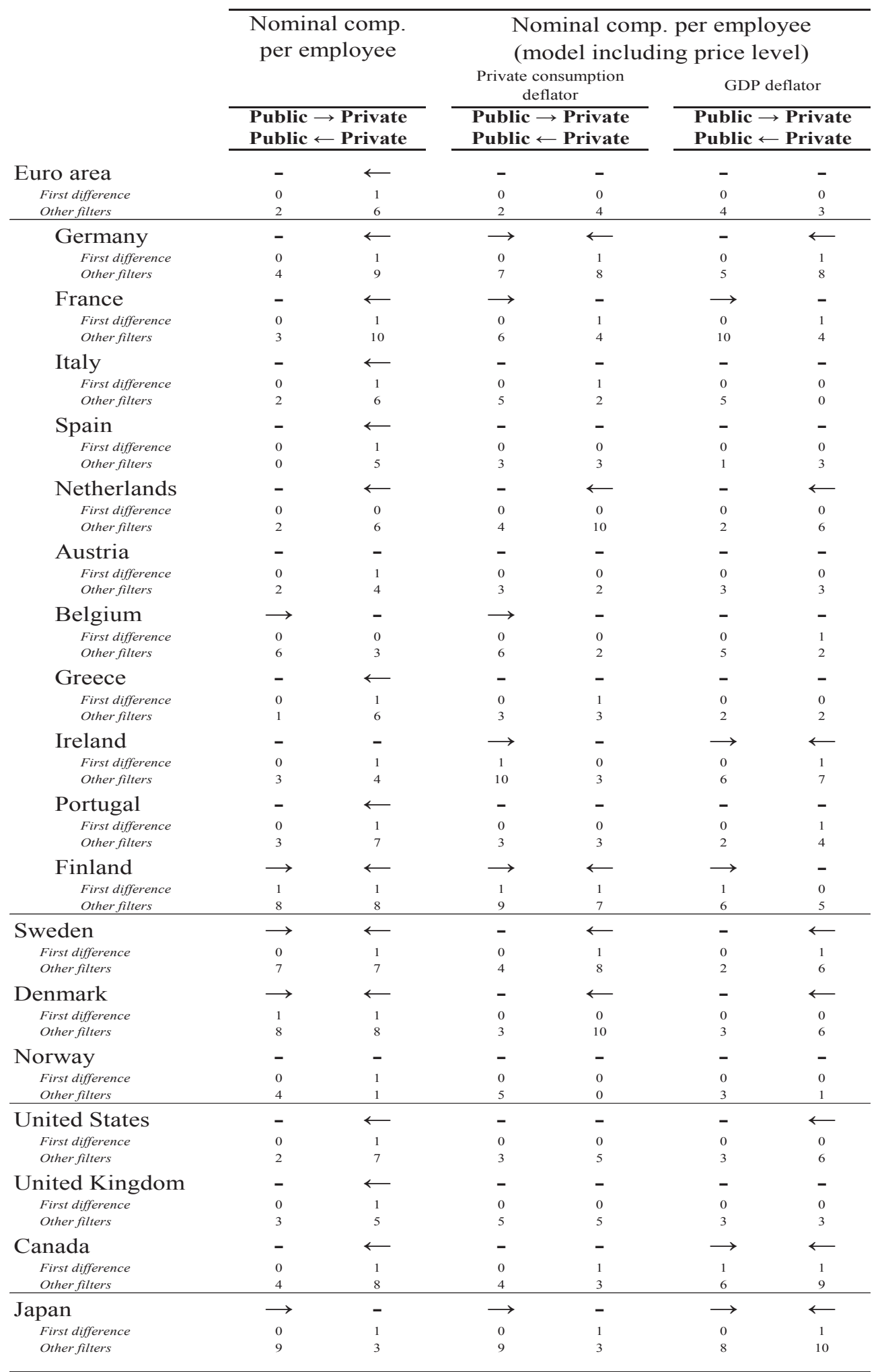


Table 4. Granger Causality tests II: VARs in levels. Annual data 1960-2006.

\begin{tabular}{|c|c|c|c|c|c|c|}
\hline & \multirow{2}{*}{\multicolumn{2}{|c|}{$\begin{array}{l}\text { Nominal } \\
\text { compensation per } \\
\text { employee }\end{array}$}} & \multicolumn{4}{|c|}{$\begin{array}{l}\text { Nominal compensation per employee } \\
\text { (model with price level) }\end{array}$} \\
\hline & & & \multicolumn{2}{|c|}{ Private consump. deflator } & \multicolumn{2}{|c|}{ GDP deflator } \\
\hline & $\begin{array}{l}\text { Public } \rightarrow \\
\text { Private }\end{array}$ & $\begin{array}{c}\text { Public } \leftarrow \\
\text { Private }\end{array}$ & $\begin{array}{l}\text { Public } \rightarrow \\
\text { Private }\end{array}$ & $\begin{array}{l}\text { Public } \leftarrow \\
\text { Private }\end{array}$ & $\begin{array}{l}\text { Public } \rightarrow \\
\text { Private }\end{array}$ & $\begin{array}{c}\text { Public } \leftarrow \\
\text { Private }\end{array}$ \\
\hline Euro area & - & $\leftarrow$ & - & $\leftarrow$ & - & $\leftarrow$ \\
\hline Germany & - & $\leftarrow$ & - & - & - & $\leftarrow$ \\
\hline France & - & $\leftarrow$ & $\rightarrow$ & $\leftarrow$ & $\rightarrow$ & $\leftarrow$ \\
\hline Italy & $\rightarrow$ & $\leftarrow$ & - & $\leftarrow$ & $\rightarrow$ & - \\
\hline Spain & - & $\leftarrow$ & - & - & - & - \\
\hline Netherlands & $\rightarrow$ & - & $\rightarrow$ & $\leftarrow$ & $\rightarrow$ & $\leftarrow$ \\
\hline Austria & - & $\leftarrow$ & - & - & - & - \\
\hline Belgium & - & $\leftarrow$ & - & - & - & - \\
\hline Greece & $\rightarrow$ & $\leftarrow$ & - & $\leftarrow$ & - & $\leftarrow$ \\
\hline Ireland & - & - & $\rightarrow$ & - & $\rightarrow$ & $\leftarrow$ \\
\hline Portugal & $\rightarrow$ & $\leftarrow$ & - & $\leftarrow$ & - & $\leftarrow$ \\
\hline Finland & $\rightarrow$ & $\leftarrow$ & $\rightarrow$ & $\leftarrow$ & $\rightarrow$ & - \\
\hline Sweden & $\rightarrow$ & $\leftarrow$ & - & $\leftarrow$ & - & $\leftarrow$ \\
\hline Denmark & $\rightarrow$ & $\leftarrow$ & $\rightarrow$ & $\leftarrow$ & - & $\leftarrow$ \\
\hline Norway & - & - & - & - & - & - \\
\hline United States & - & $\leftarrow$ & - & $\leftarrow$ & - & $\leftarrow$ \\
\hline United Kingdom & - & $\leftarrow$ & - & $\leftarrow$ & - & $\leftarrow$ \\
\hline Canada & - & $\leftarrow$ & - & $\leftarrow$ & $\rightarrow$ & - \\
\hline Japan & - & $\leftarrow$ & $\rightarrow$ & $\leftarrow$ & - & $\leftarrow$ \\
\hline
\end{tabular}


Table 5. Granger Causality tests II Con't (Wages and Prices): VARs in levels. Annual data 1960-2006.

Nominal compensation per employee (model with price level)

Private consump. deflator

\begin{tabular}{|c|c|c|c|c|}
\hline & \\
\hline & $\begin{array}{c}\text { Prices } \rightarrow \\
\text { Public wages }\end{array}$ & $\begin{array}{c}\text { Prices } \rightarrow \\
\text { Private wages }\end{array}$ & $\begin{array}{c}\text { Public wages } \\
\rightarrow \text { Prices }\end{array}$ & $\begin{array}{l}\text { Private wages } \\
\rightarrow \text { Prices }\end{array}$ \\
\hline Euro area & $\rightarrow$ & $\rightarrow$ & $\rightarrow$ & $\rightarrow$ \\
\hline Germany & $\rightarrow$ & $\rightarrow$ & - & $\rightarrow$ \\
\hline France & $\rightarrow$ & $\rightarrow$ & - & $\rightarrow$ \\
\hline Italy & $\rightarrow$ & $\rightarrow$ & - & $\rightarrow$ \\
\hline Spain & $\rightarrow$ & $\rightarrow$ & $\rightarrow$ & $\rightarrow$ \\
\hline Netherlands & $\rightarrow$ & $\rightarrow$ & $\rightarrow$ & - \\
\hline Austria & - & $\rightarrow$ & - & $\rightarrow$ \\
\hline Belgium & - & - & - & $\rightarrow$ \\
\hline Greece & - & $\rightarrow$ & - & $\rightarrow$ \\
\hline Ireland & $\rightarrow$ & $\rightarrow$ & $\rightarrow$ & $\rightarrow$ \\
\hline Portugal & - & $\rightarrow$ & $\rightarrow$ & - \\
\hline Finland & $\rightarrow$ & $\rightarrow$ & $\rightarrow$ & $\rightarrow$ \\
\hline Sweden & - & $\rightarrow$ & $\rightarrow$ & $\rightarrow$ \\
\hline Denmark & $\rightarrow$ & $\rightarrow$ & $\rightarrow$ & $\rightarrow$ \\
\hline Norway & $\rightarrow$ & $\rightarrow$ & $\rightarrow$ & - \\
\hline United States & $\rightarrow$ & $\rightarrow$ & - & - \\
\hline United Kingdom & $\rightarrow$ & $\rightarrow$ & - & - \\
\hline Canada & $\rightarrow$ & $\rightarrow$ & $\rightarrow$ & - \\
\hline Japan & $\rightarrow$ & $\rightarrow$ & $\rightarrow$ & $\rightarrow$ \\
\hline
\end{tabular}

GDP deflator

\begin{tabular}{|c|c|c|c|}
\hline $\begin{array}{c}\text { Prices } \rightarrow \\
\text { Public wages }\end{array}$ & $\begin{array}{c}\text { Prices } \rightarrow \\
\text { Private wages }\end{array}$ & $\begin{array}{c}\text { Public wages } \\
\rightarrow \text { Prices }\end{array}$ & $\begin{array}{c}\text { Private wages } \\
\rightarrow \text { Prices }\end{array}$ \\
\hline$\rightarrow$ & $\rightarrow$ & - & $\rightarrow$ \\
\hline$\rightarrow$ & $\rightarrow$ & - & $\rightarrow$ \\
\hline$\rightarrow$ & $\rightarrow$ & $\rightarrow$ & $\rightarrow$ \\
\hline$\rightarrow$ & $\rightarrow$ & $\rightarrow$ & $\rightarrow$ \\
\hline$\longrightarrow$ & $\rightarrow$ & $\rightarrow$ & $\longrightarrow$ \\
\hline$\rightarrow$ & $\rightarrow$ & $\rightarrow$ & $\rightarrow$ \\
\hline$\rightarrow$ & $\rightarrow$ & - & $\rightarrow$ \\
\hline - & - & $\rightarrow$ & $\rightarrow$ \\
\hline$\rightarrow$ & - & - & $\rightarrow$ \\
\hline$\rightarrow$ & $\rightarrow$ & - & - \\
\hline - & $\rightarrow$ & - & $\rightarrow$ \\
\hline - & $\rightarrow$ & $\rightarrow$ & $\rightarrow$ \\
\hline - & $\rightarrow$ & $\rightarrow$ & $\rightarrow$ \\
\hline$\rightarrow$ & $\rightarrow$ & $\rightarrow$ & $\rightarrow$ \\
\hline$\rightarrow$ & $\rightarrow$ & - & - \\
\hline$\rightarrow$ & $\rightarrow$ & $\rightarrow$ & $\rightarrow$ \\
\hline$\rightarrow$ & $\rightarrow$ & - & $\rightarrow$ \\
\hline$\rightarrow$ & $\rightarrow$ & - & - \\
\hline$\rightarrow$ & $\rightarrow$ & $\rightarrow$ & $\rightarrow$ \\
\hline
\end{tabular}


Table 6. Institutional determinants of public wage leadership.

The dependent variable takes a value of 1 if public wages cause private wages. Method of estimation: Probit.

Specification Specification Specification Specification Specification

(1)

(2)

(3)

(4)

(5)

GDP deflator Private cons. Def.

\section{OECD labour market indicators}

1) Index of bargaining coordination

2) Index of bargaining centralisation

$-0.083$

0.167

$-0.255$

0.125

$[2.73]^{* *}$

[0.66]

[1.07]

[1.37]

[0.71]

3) Employment protection legislation

$-0.022$

[0.26]

4) Union membership/employment

$-0.318$

$-0.838$

$-1.24$

$-0.929$

$-0.873$

$[3.16]^{* *}$

[4.97]**

$[5.25]^{* *}$

$[3.61]^{* *}$

$[3.77]^{* *}$

0.003

0.022

0.011

0.026

0.02

[1.33]

$[3.60]^{* *}$

[1.59]

$[2.72]^{* *}$

[2.52 $]^{*}$

\section{Product market regulation index}

5) Product market regulation index

$\begin{array}{ccccc}0.434 & 1.119 & 1.857 & 1.309 & 1.112 \\ {[1.76]} & {[3.84]^{* *}} & {[4.39]^{* *}} & {[3.22]^{* *}} & {[2.58]^{* *}}\end{array}$

\section{Other control variables}

6) KOF index of globalisation

$\begin{array}{lll}-0.011 & -0.002 & -0.005\end{array}$

$-0.005$

0

$-0.006$

$[2.85]^{* *}$

[1.05]

[0.05]

[0.82]

7) Public employment ratio

5.645

[2.47]*

\section{WDN variables}

8) Government involvement in collective bargaining

0.103

0.801

0.643

$[2.67]^{* *}$

$[4.31]^{* *}$

[0.28]

$[4.03]^{* *}$

$[3.38]^{* *}$

9) High coverage by indexation mechanisms (76-100\%)

$-0.214$

$-0.626$

$-0.552$

$-0.623$

$-0.695$

[1.51]

$[4.96]^{* *}$

$[2.85]^{* *}$

$[4.15]^{* *}$

$[3.65]^{* *}$

10) Dominant level of collective bargaining: sectoral

11) Dominant level of collective bargaining: occupational

0.374

0.505

0.533

0.112

$[1.70] \quad[2.40]^{*}$

[1.81]

[0.35]

$-0.442$

$-0.45$

$-0.423$

$-0.473$

$[3.25]^{* *}$

[3.48]**

$[2.38]^{*}$

[2.30 *

12) Dominant level of collective bargaining: national

13) Dominant level of collective bargaining: regional

0.365

0.473

0.475

0.266

[1.43]

[1.97]*

[1.32]

[0.68]

$0.341 \quad 0.325$

0.378

0.335

[2.38]*

[2.22]*

[1.75]

[1.72]

14) Dominant level of collective bargaining: company-level

$-0.469$

$-0.521$

[4.69]**

$[5.25]^{* *}$

$-0.376$

$-0.629$

360

360

[2.84]**

$[4.57]^{* *}$

Number of observations (maximum possible 432)

360

360

180

180

Notes: Robust z statistics in brackets: * significant at 5\%; ** significant at $1 \%$. The estimated coefficients shown in this table yield the marginal effect of a change in independent variables on the probability of public wage causation. The estimations include method dummies and deflator dummies in columns 1 and 2 . 
Figure 1. The evolution of relative wages per employee in the OECD: ratio of wages per employee in the public sector over wages per employee in the private sector.
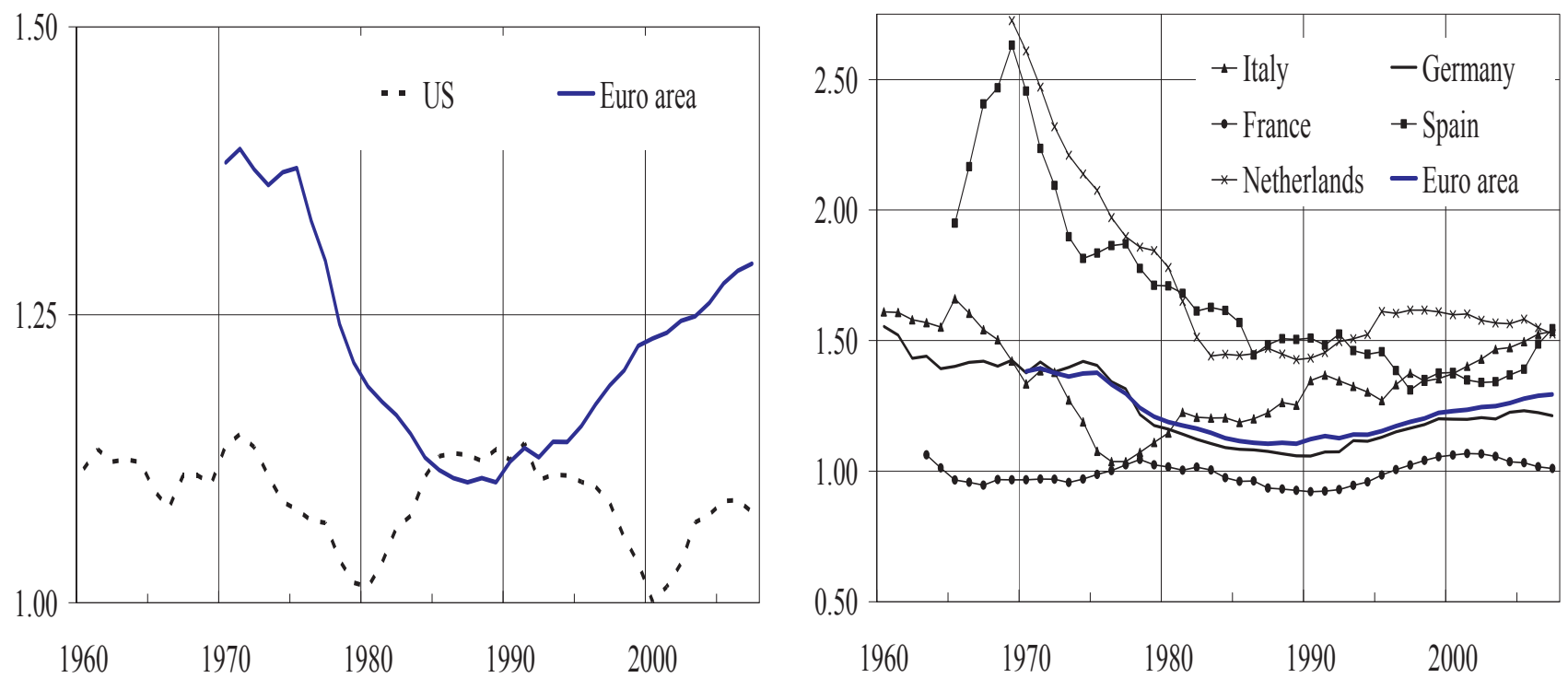
Figure 2. The growth rate of nominal wages per employee (left panels) and employment (right panels)

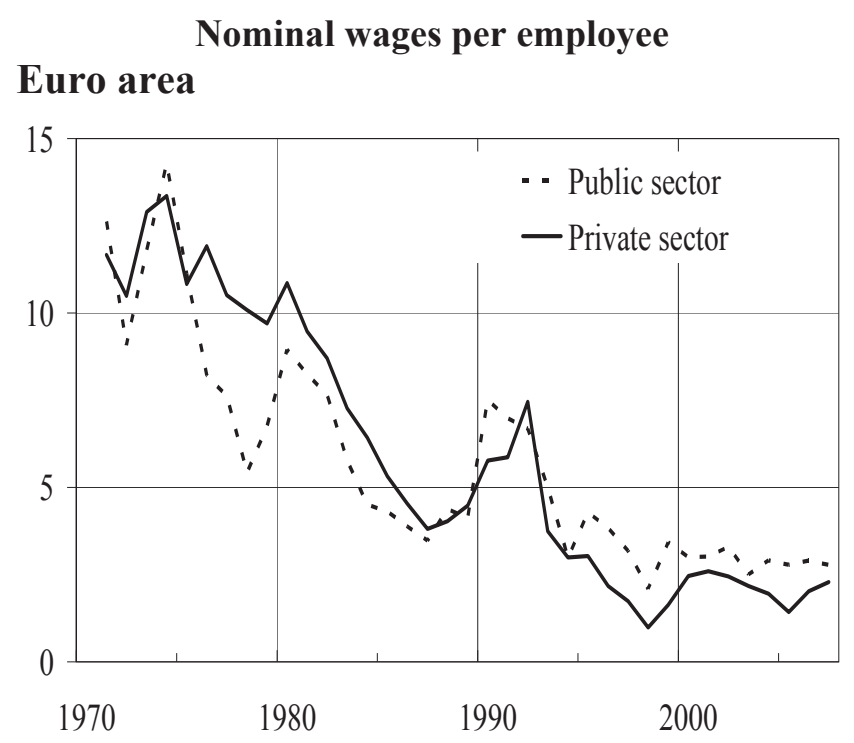

\section{United States}
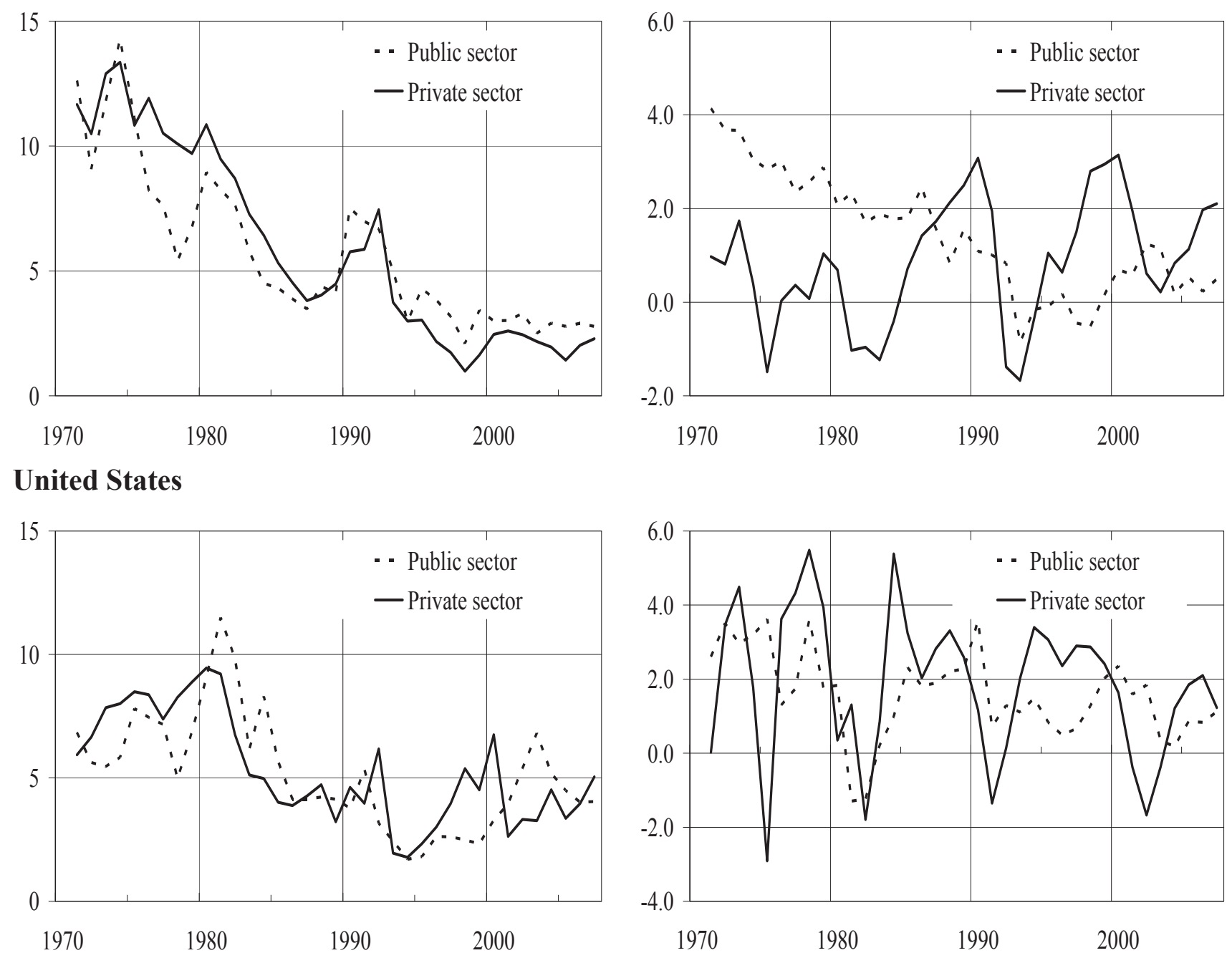
Figure 3. Correlations of forecast errors from VARs between public and private wages per employee. $h$-step ahead forecast errors, $h=1,2, \ldots, 9$.

VAR specification with unit root imposed. Sample 1960-2006.

\section{Euro area}

Nominal compensation per employee

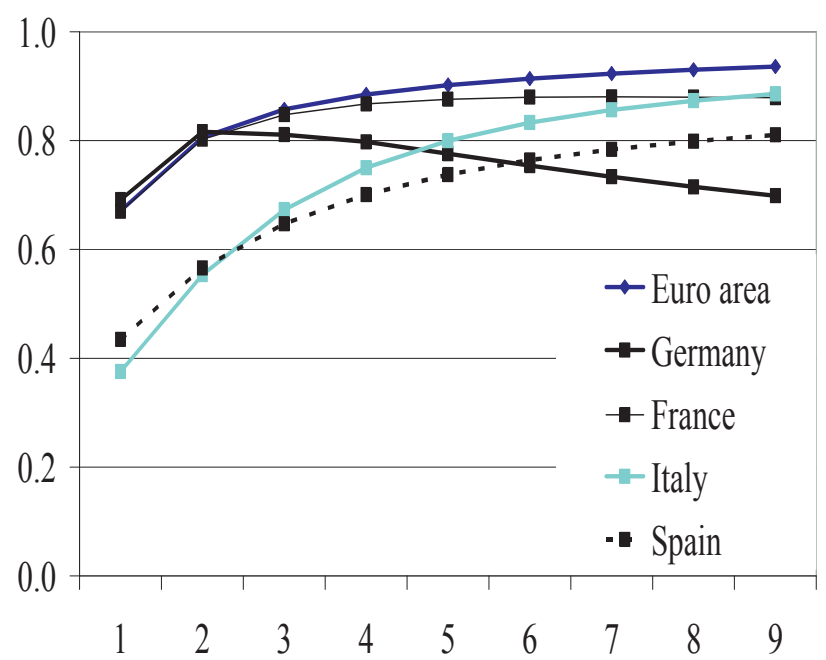

\section{Euro area}

Real compensation per employee (private consumption deflator)

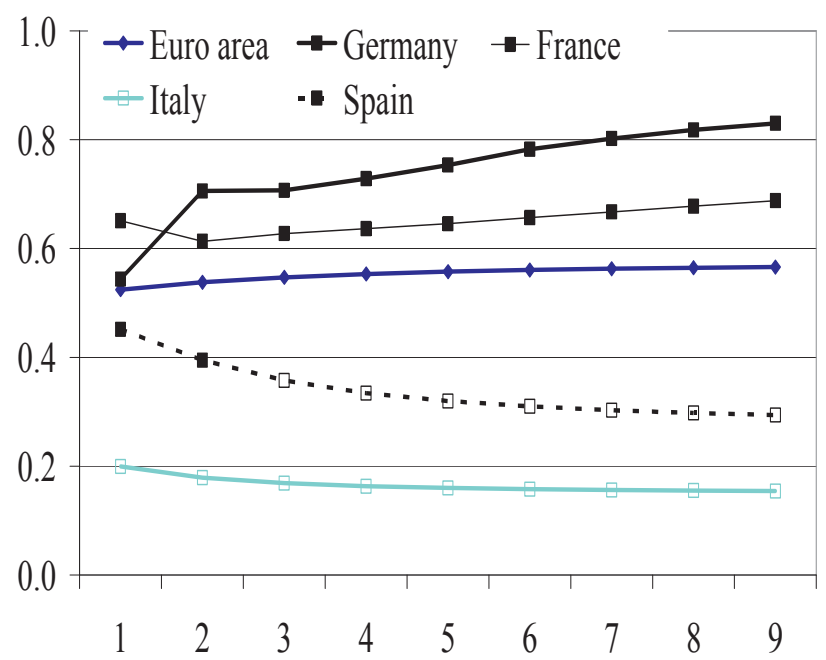

Non euro area

Nominal compensation per employee

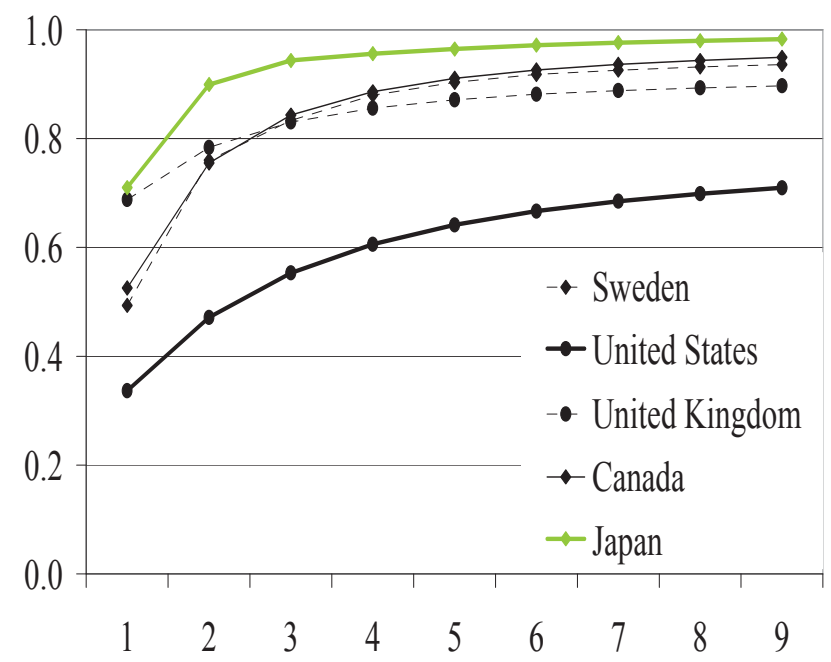

Non euro area

Real compensation per employee (private consumption deflator)

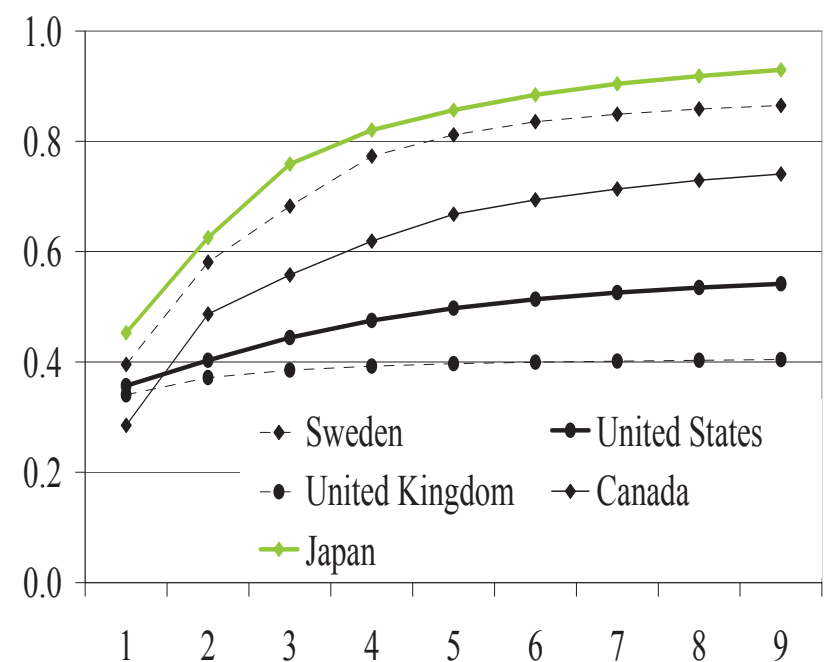

Note: These panels plot the correlation coefficients of the h-period ahead forecast errors of the indicated variables. Significance levels are based on Monte-Carlo confidence intervals. Markers filled-in with colour denote significance at the 5\% level, while markers filled-in white denote correlations not significantly different from zero at the $5 \%$ level. 


\section{Appendix A. Description of the detrending methods used in Section 3}

The following methods are used in Section 3 to estimate detrended variables:

First difference filter: First order differencing takes the cycle to be the variable in first differences. In other words, it assumes that the trend is the lagged variable, or similarly the series is a random walk with no drift. Therefore $y_{\mathrm{t}}$ can be represented as: $y_{t}=y_{t-1}+C_{t}+\varepsilon_{t}$, where the trend is $T_{\mathrm{t}}=y_{\mathrm{t}-1}$ and an estimate of the detrended component is obtained as $y_{\mathrm{t}}-y_{\mathrm{t}-1}$.

Deterministic trends: $T_{\mathrm{t}}$ is taken to be a deterministic process which can be approximated with polynomial functions of time such that $T_{\mathrm{t}}=f(\mathrm{t}), f(\mathrm{t})=\mathrm{a}_{0}+\mathrm{a}_{1} \mathrm{t}^{+} \mathrm{a}_{2} \mathrm{t}^{2} \ldots+\mathrm{a}_{\mathrm{h}} \mathrm{t}^{h} . h$ is the order of the polynomial. Even though the disturbance may be serially correlated, it can be shown that the unknown parameters in $f(\mathrm{t})$ can be estimated efficiently by ordinary least squares. In this paper we take $\mathrm{h}=2$.

Hodrick-Prescott: The Hodrick and Prescott filter (HP Filter) extracts a stochastic trend that moves smoothly over time and is not correlated with the cycle. The HP filter crucially depends on a smoothing parameter $(\lambda)$ that penalizes large fluctuations. A large $\lambda$ implies a higher penalty and, therefore, a smoother cycle. For annual data the value of $\lambda$ typically used has been 100 , although recent studies suggest that lower values leave cycles of more reasonable duration. In particular, it has been shown that $\lambda$ values of 6.25 deliver cycles of similar length to the cycles resulting with quarterly data when using $\lambda$ of 1600 , which is the standard value. We calculate two versions of the HP filter, one with $\lambda$ equal 100 and another one with $\lambda$ equal 6.25 .

Band pass filter: We use an optimal finite sample approximation for the band pass filter as proposed by Christiano and Fitzgerald (2003). The band pass filter is a frequency domain based filter. It assumes that the trend component has the power at lower frequencies of the spectrum. The choice in this procedure is to define the limits of the frequency band, say $p_{l}$ and $p_{u}$, to isolate the cyclical component with a period of oscillation between $p_{l}$ and $p_{u}$. We make two choices for the cycle length between 2 and 8 years, $\left\{p_{l}, p_{u}\right\}=\{2,8\}$, and between 2 and 6 years, $\left\{p_{l}, p_{u}\right\}=\{2,6\}$, removing thus all the fluctuations that have a periodicity larger than $8(6)$ or smaller the 2 years.

Unobserved components models: We consider structural time series models in the vein of the basic structural model in Harvey (1989). The trend is specified as $T_{\mathrm{t}}=T_{\mathrm{t}-1}+S_{\mathrm{t}}+\varepsilon_{\mathrm{t}}^{T}, S_{\mathrm{t}}=S_{\mathrm{t}-1}+\varepsilon_{\mathrm{t}}^{S}$, where $\varepsilon_{\mathrm{t}}^{T}$ and $\varepsilon_{\mathrm{t}}^{S}$ are mutually uncorrelated white noise disturbances with zero means and variances $\sigma_{T}{ }^{2}$ and $\sigma_{S}{ }^{2}$ respectively. This model is known as the local linear trend model. The cyclical component $C_{\mathrm{t}}$ is assumed to be a stochastic cycle, a mixture of sine-cosine waves in a given period shocked with disturbances. 
The estimated models for the empirical exercise are the following. First, we take the basic structural model and adjust the smoothness of the trend, looking at three cases: (i) linear trend model $\left(\sigma_{T}{ }^{2}=0\right.$ and $\left.\sigma_{S}{ }^{2}=0\right)$ plus cycle; (ii) local level model $\left(\sigma_{T}{ }^{2}=0\right)$ plus cycle; and (iii) local linear trend model plus cycle. Next, we preserve assumptions (ii) and (iii) for the trend, and adjust the model for the cycle allowing for cycles of period 2 to 6 years to be estimated (not just imposed as in the basic case) using the so-called DHR (Dynamic Harmonic Regression) methods as in Young, Pedregal and Tych (1999). Thus, all in all, 5 different unobserved components models are fitted to the data. 


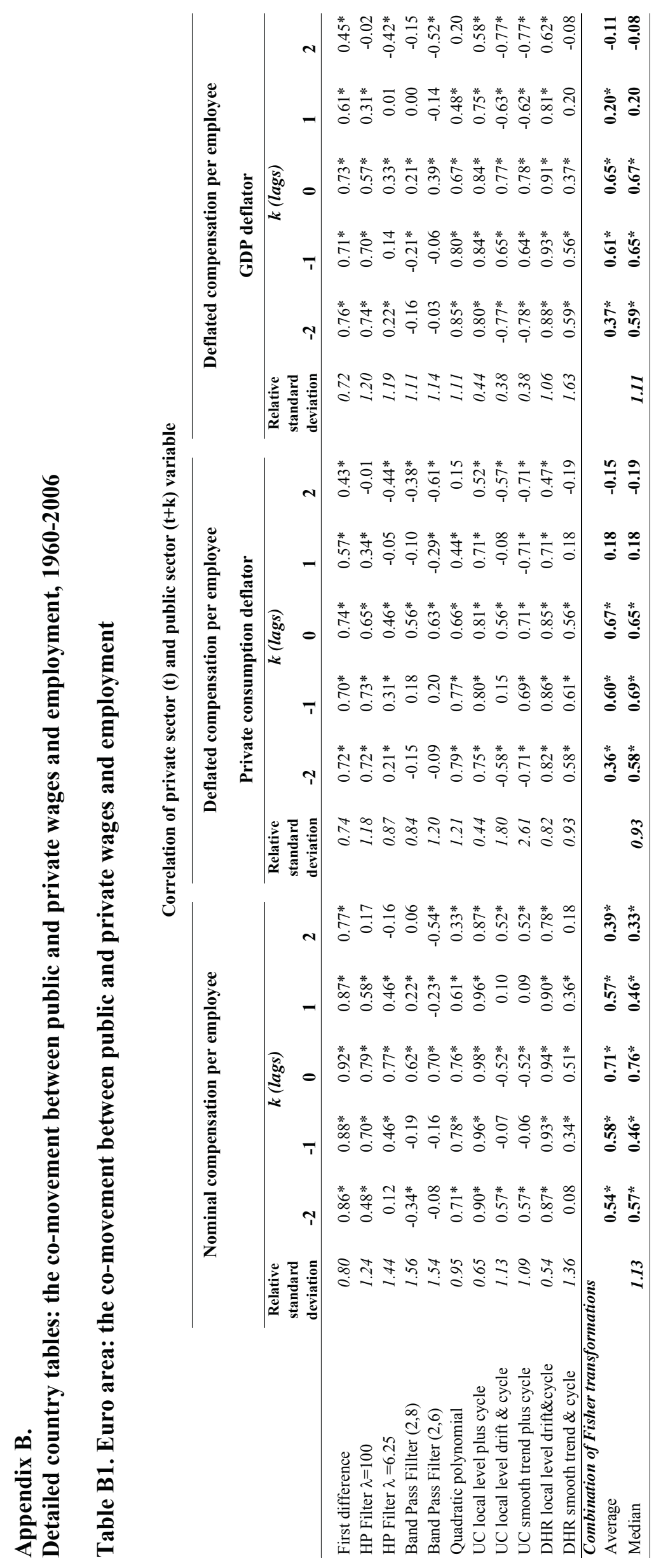




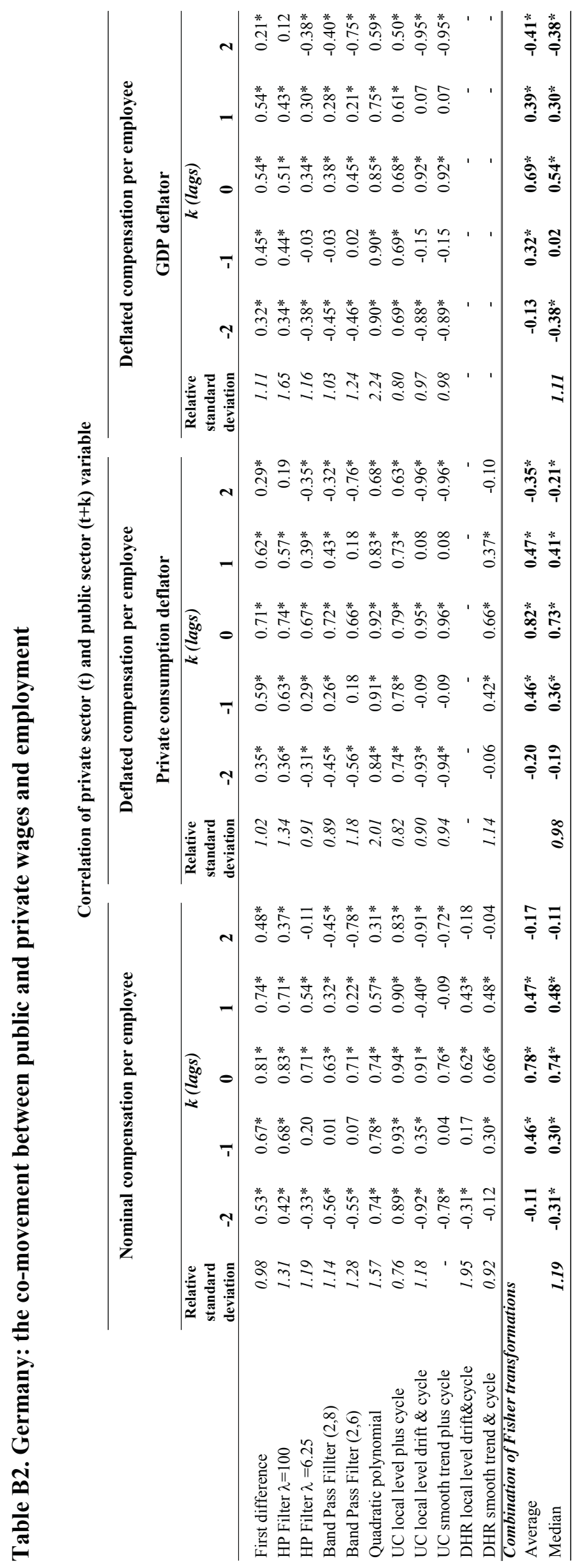




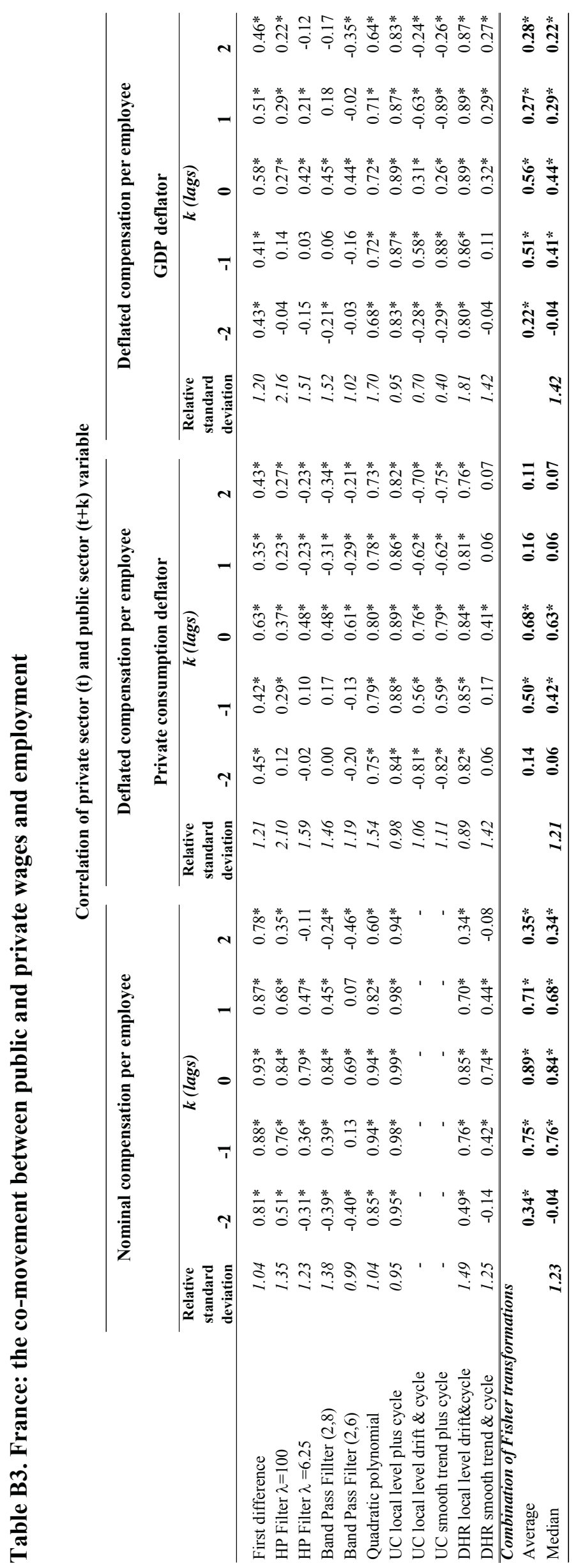




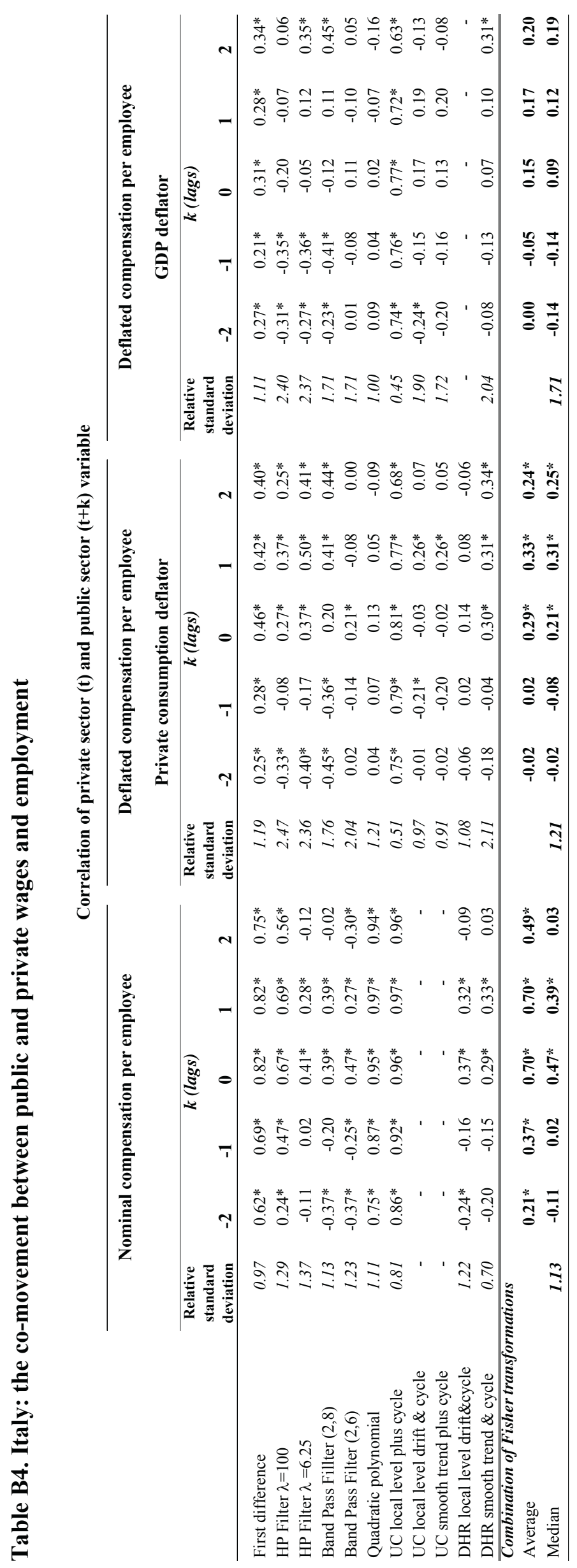




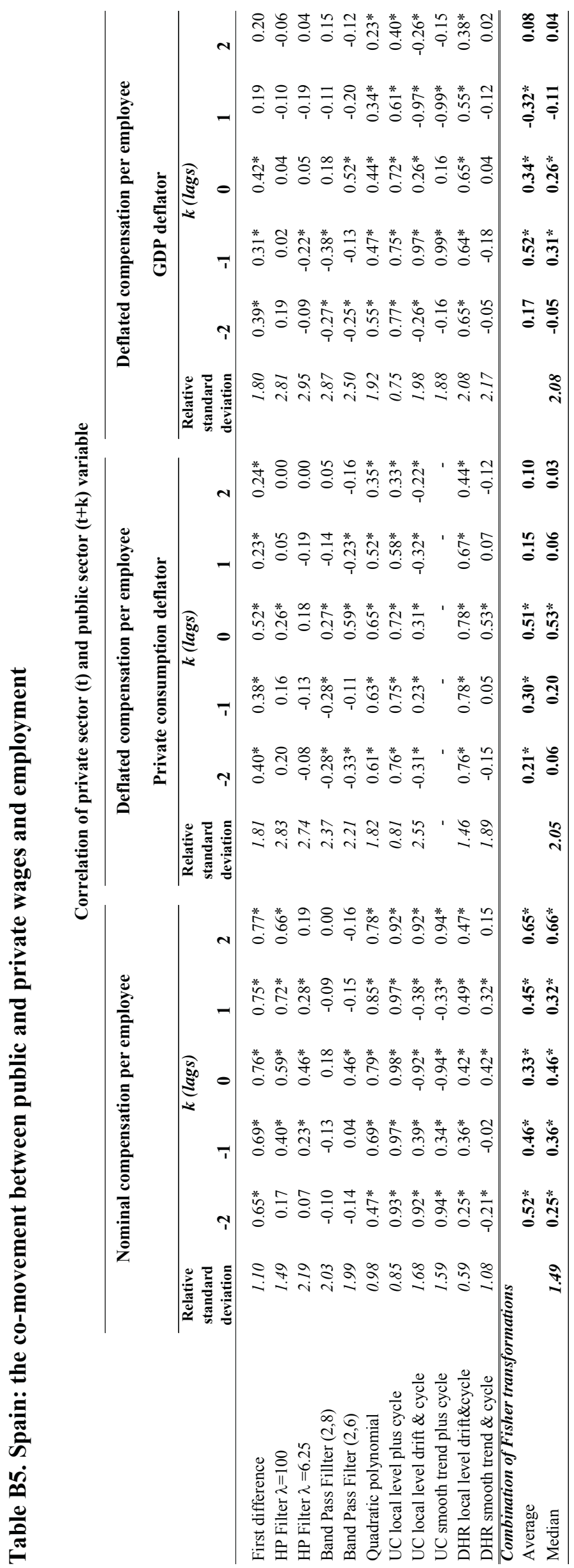




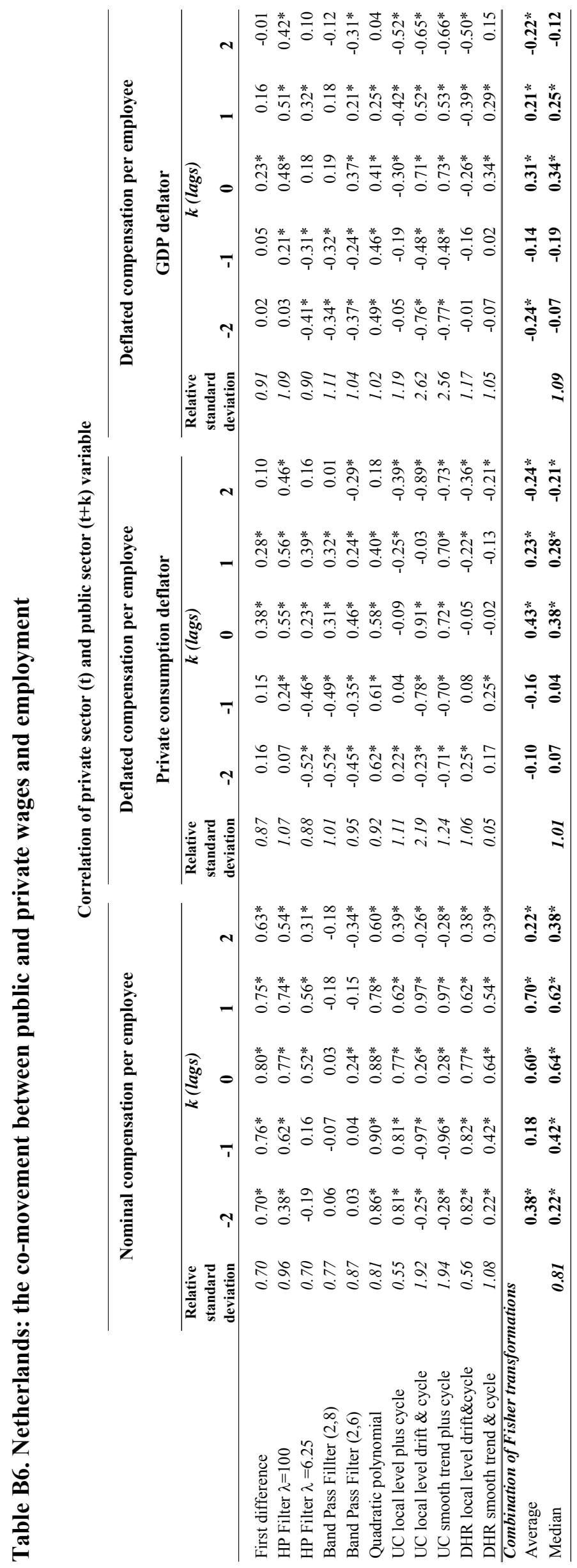




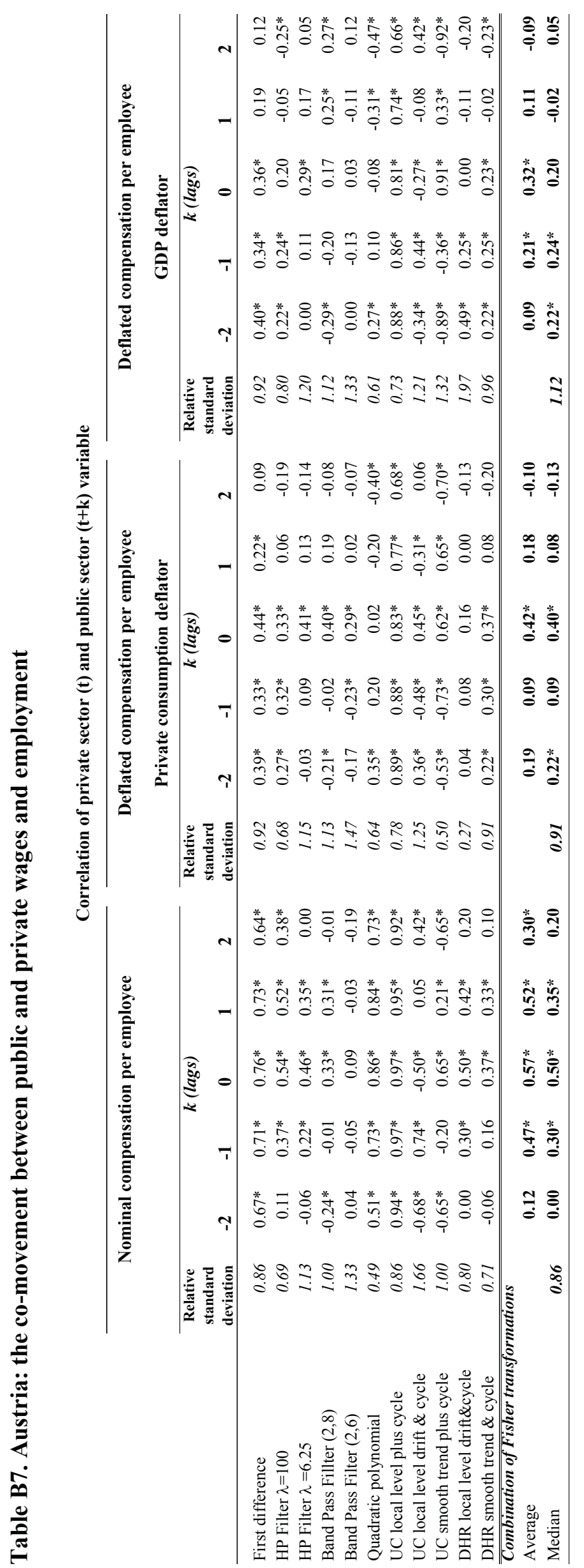




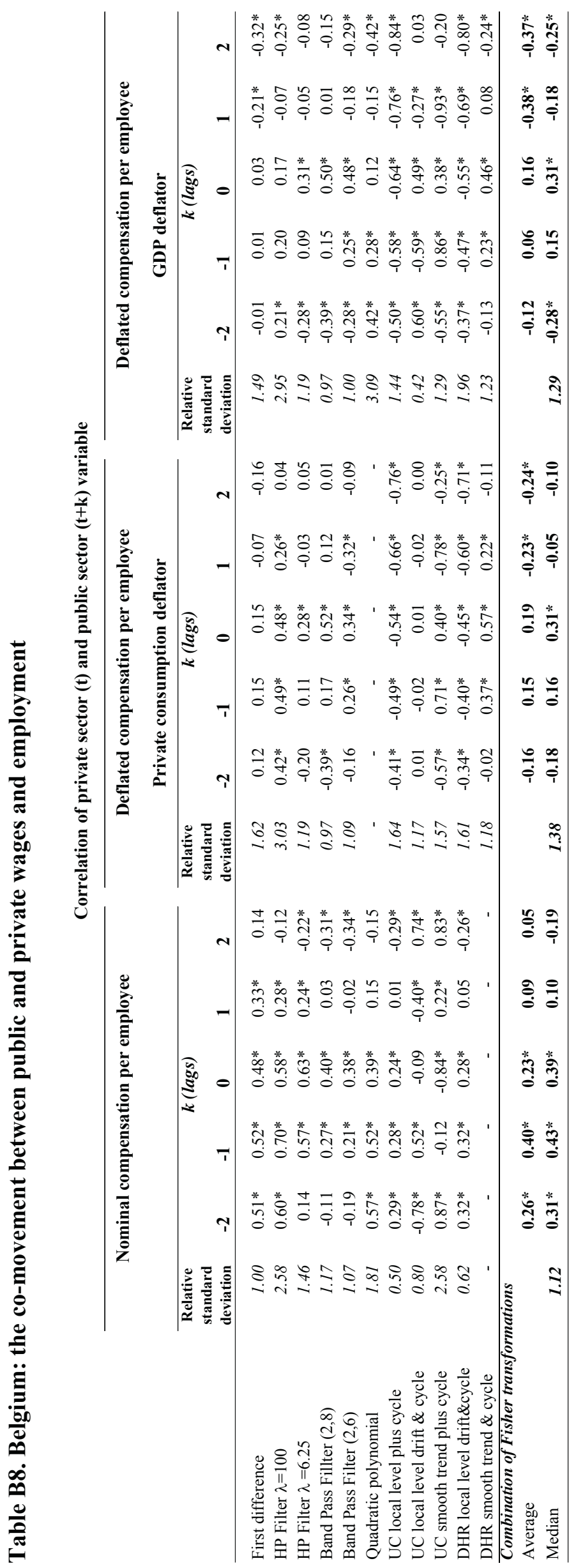




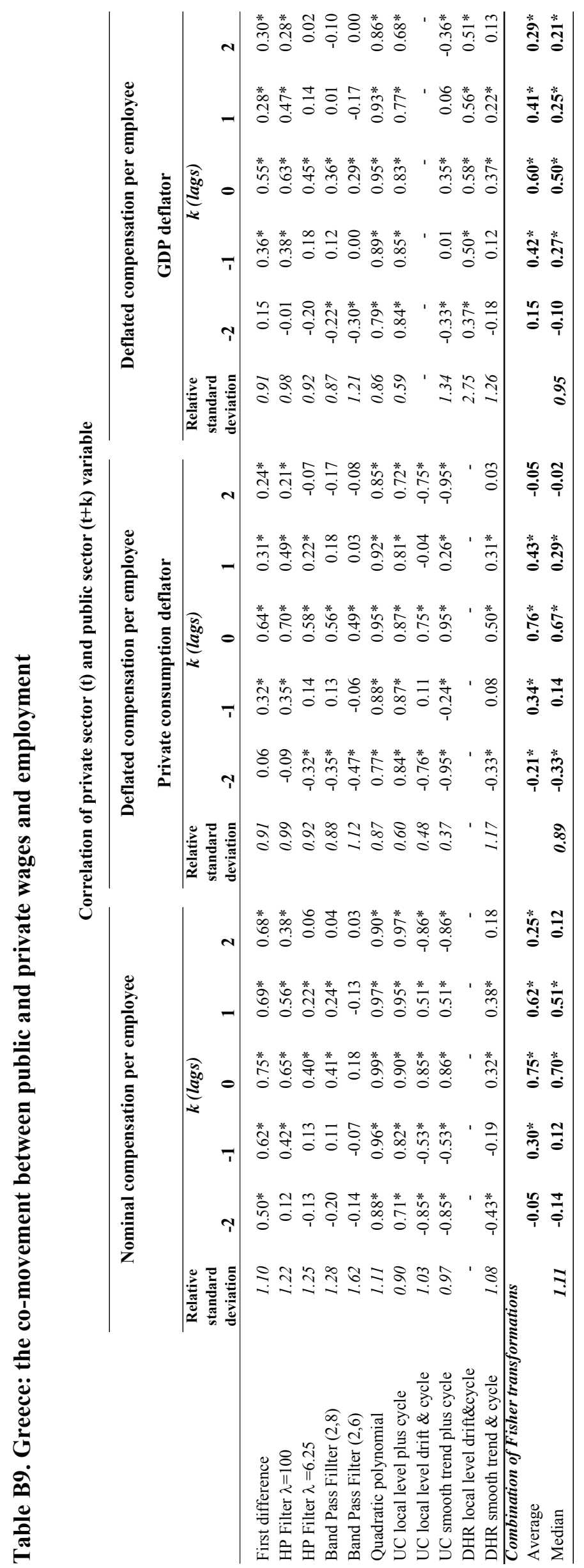




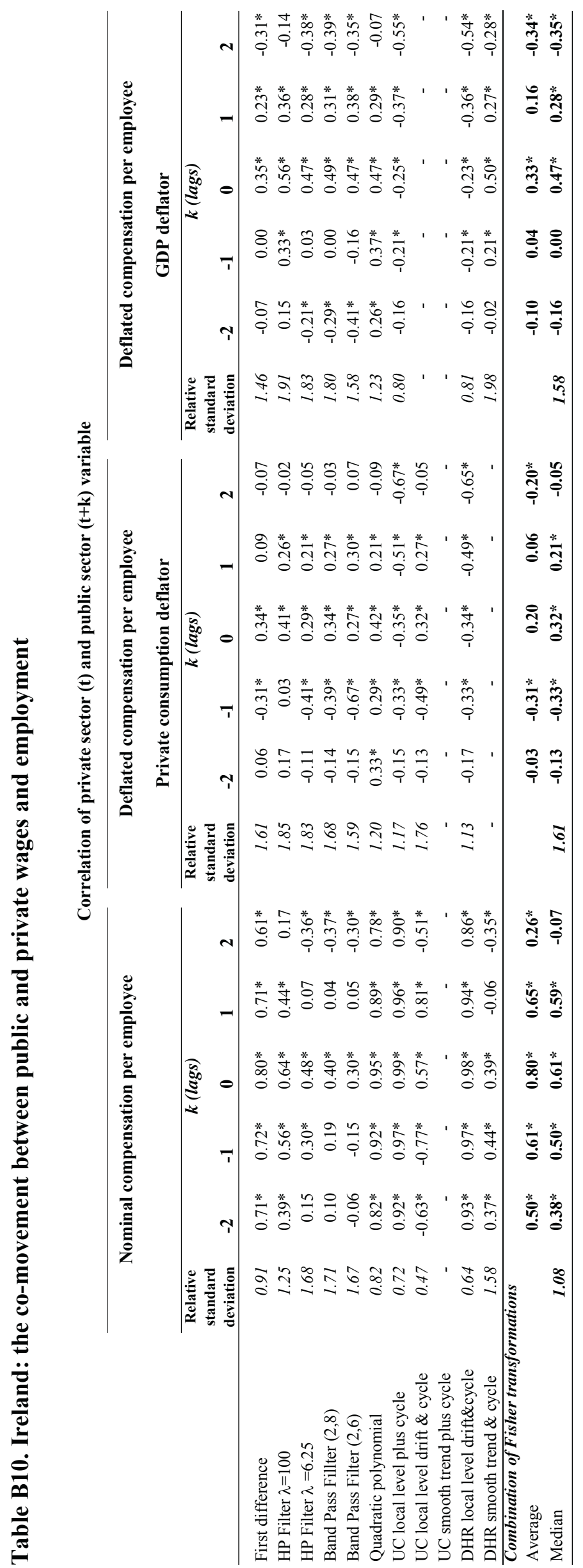




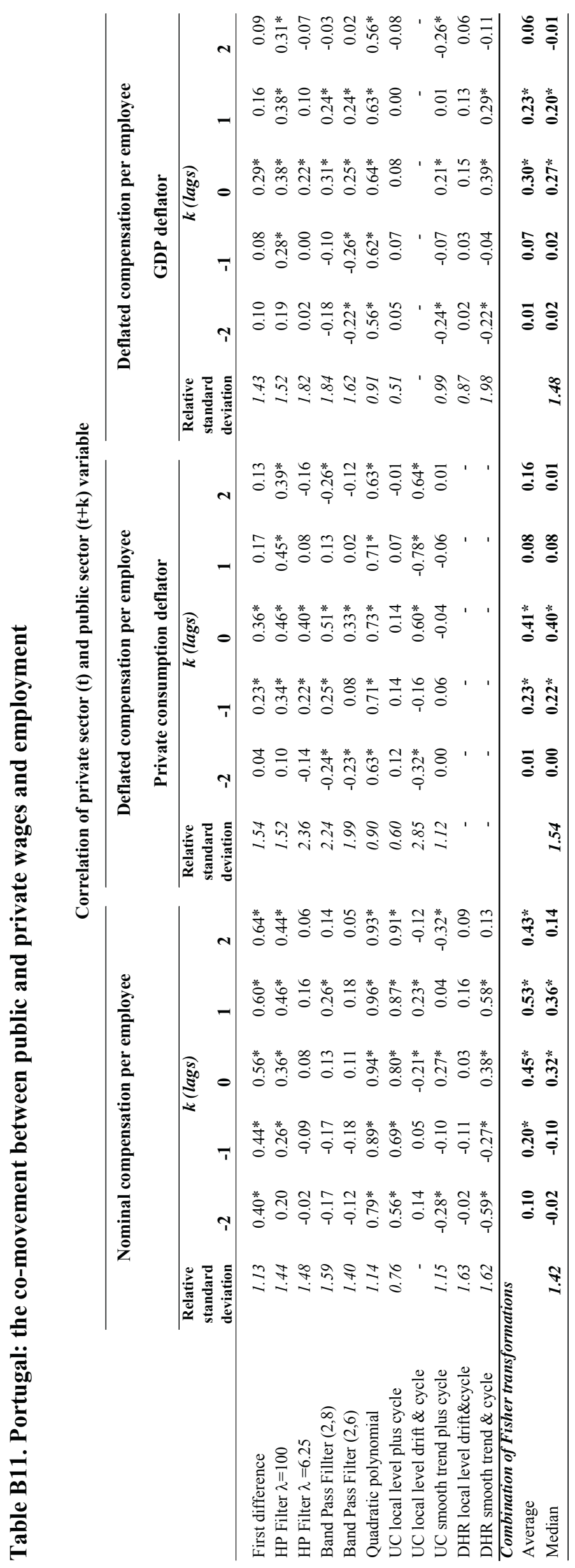




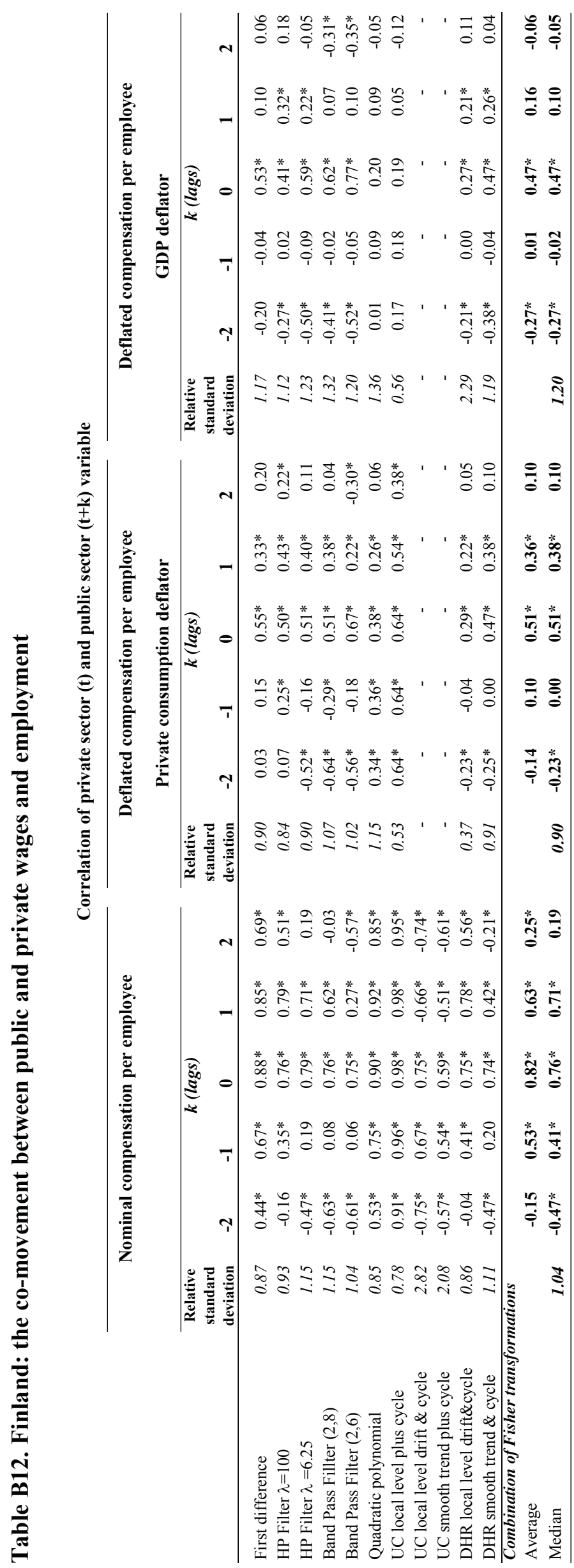




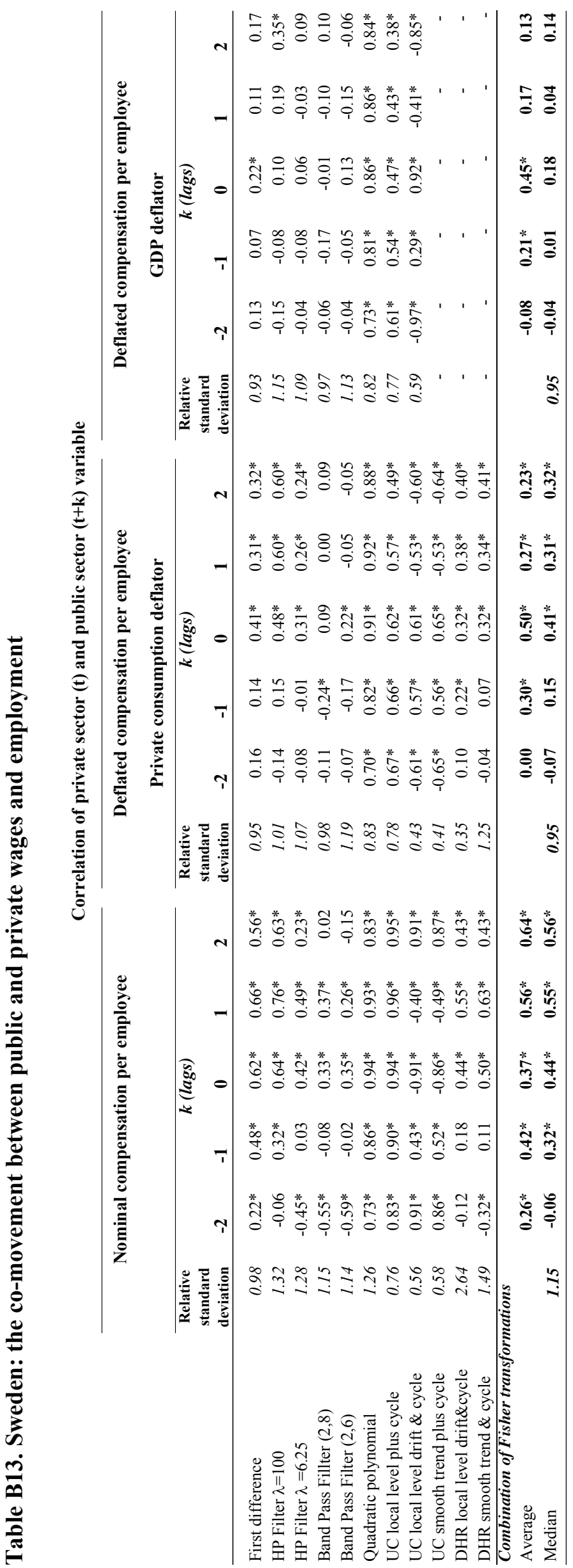




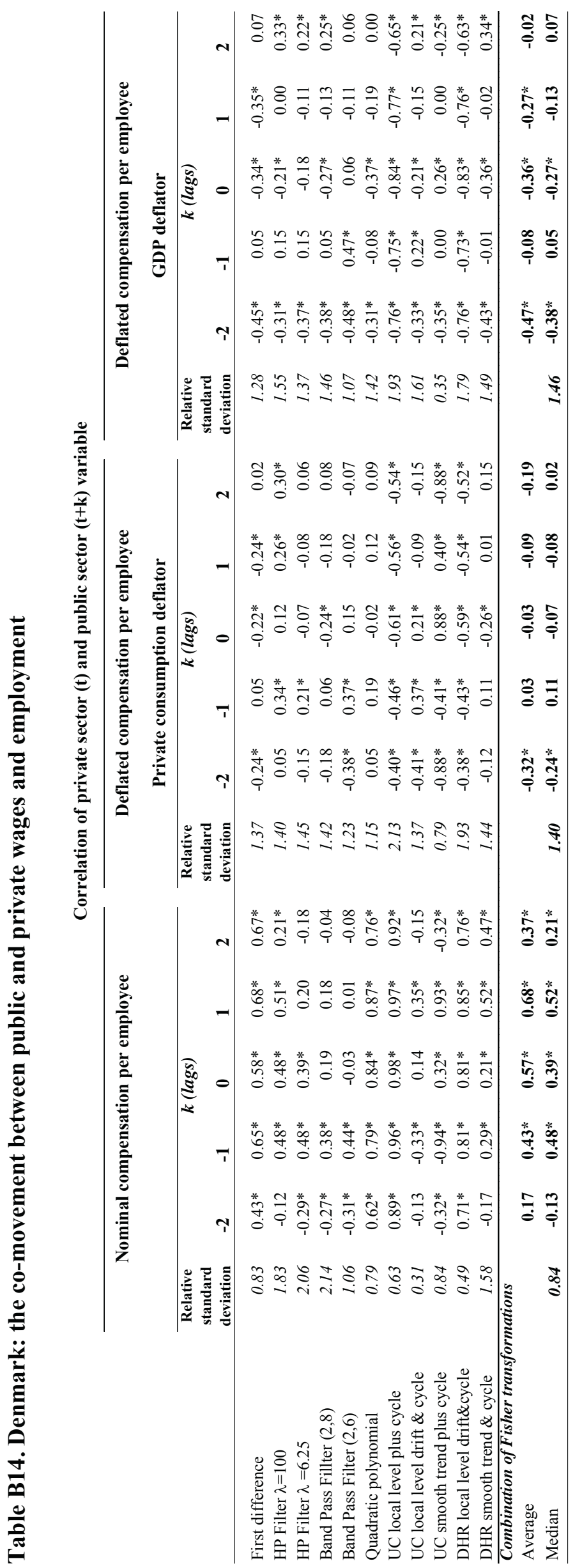




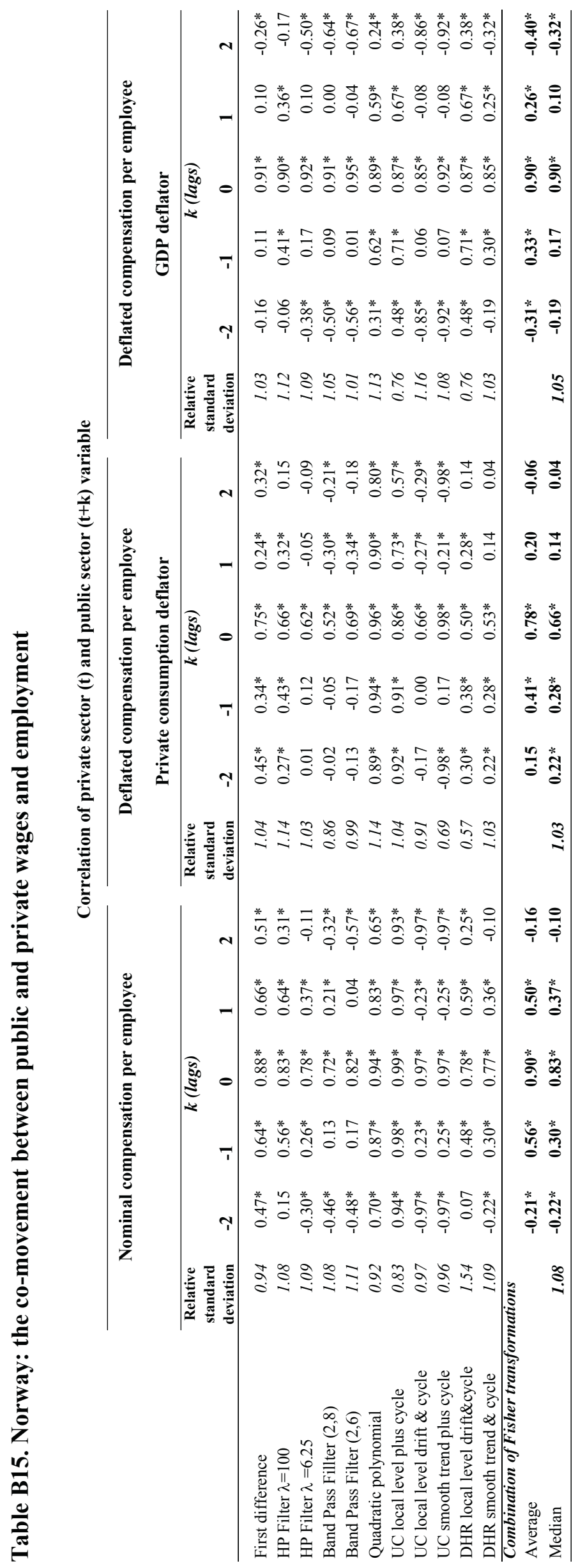




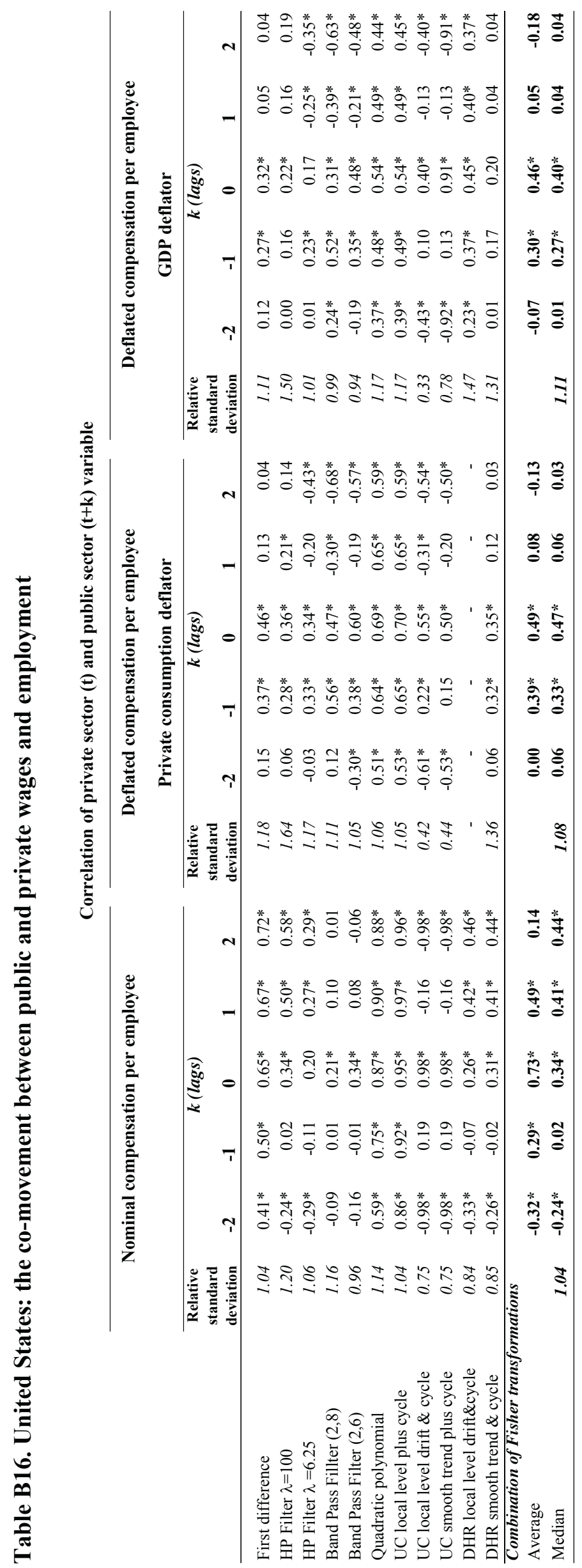




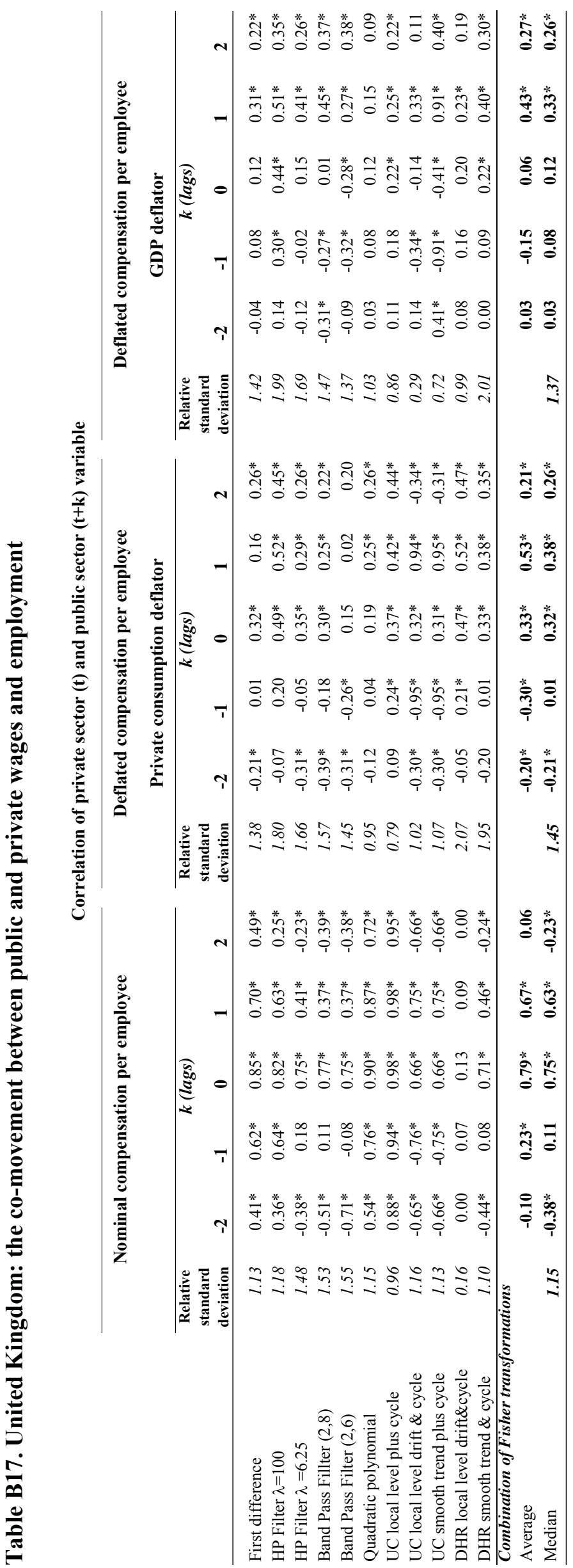




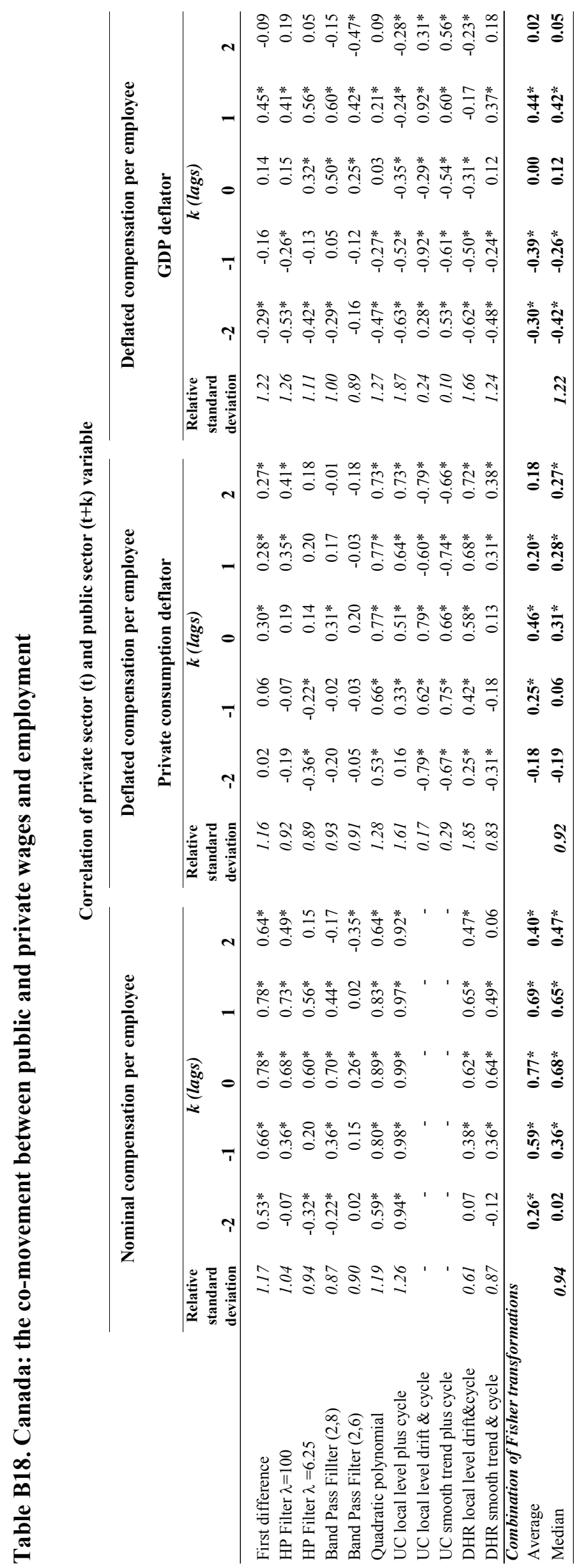




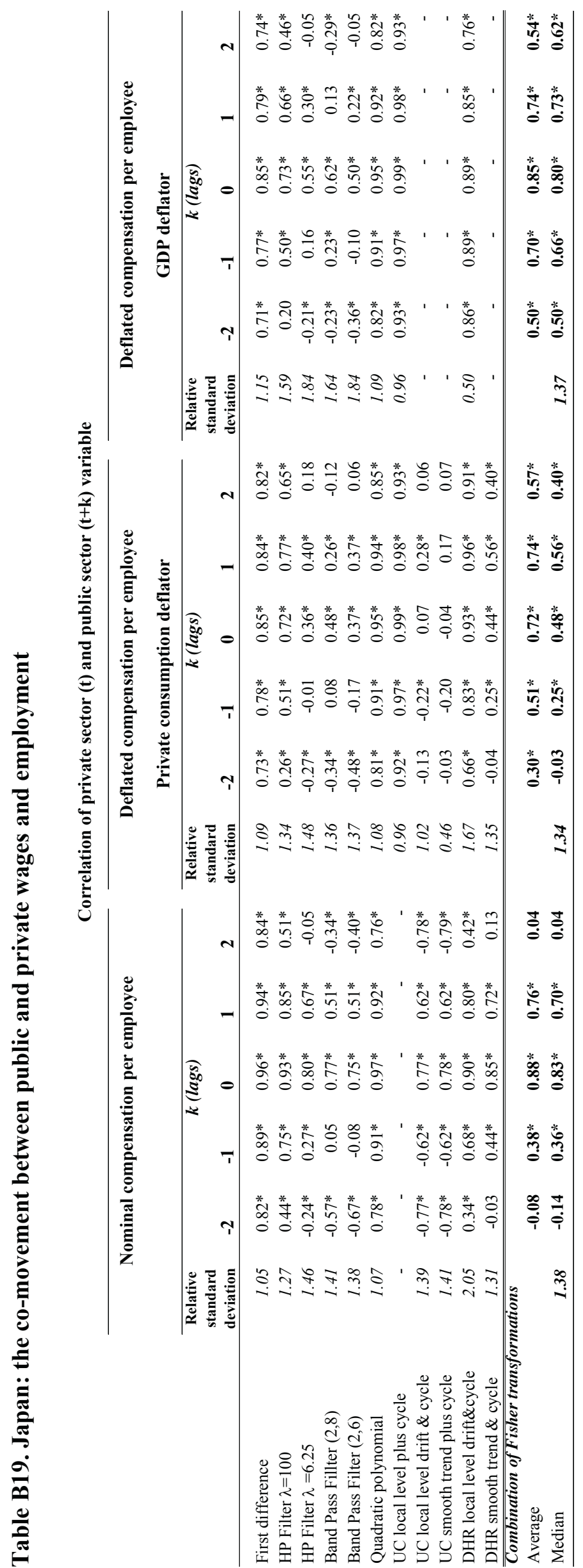




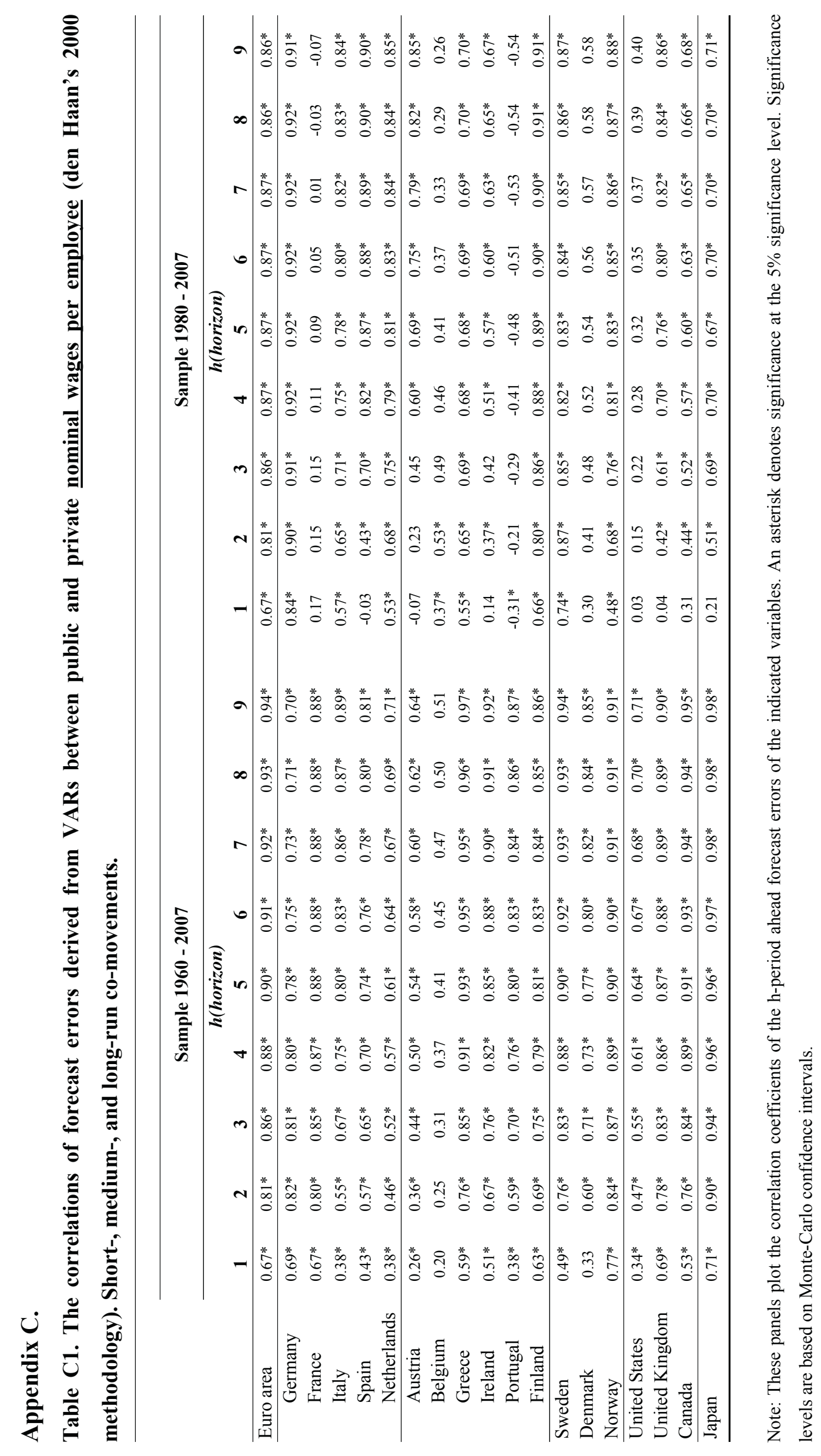




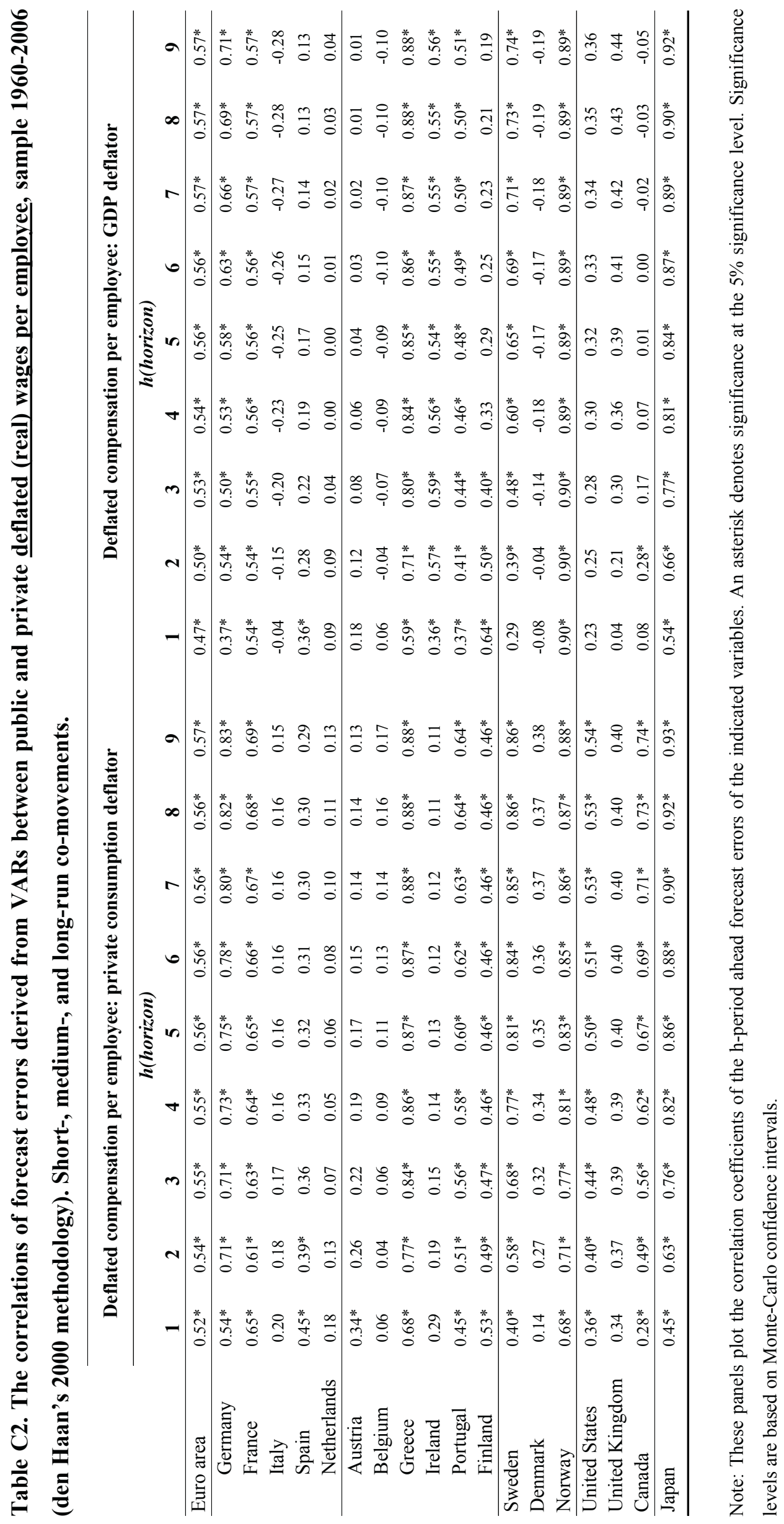




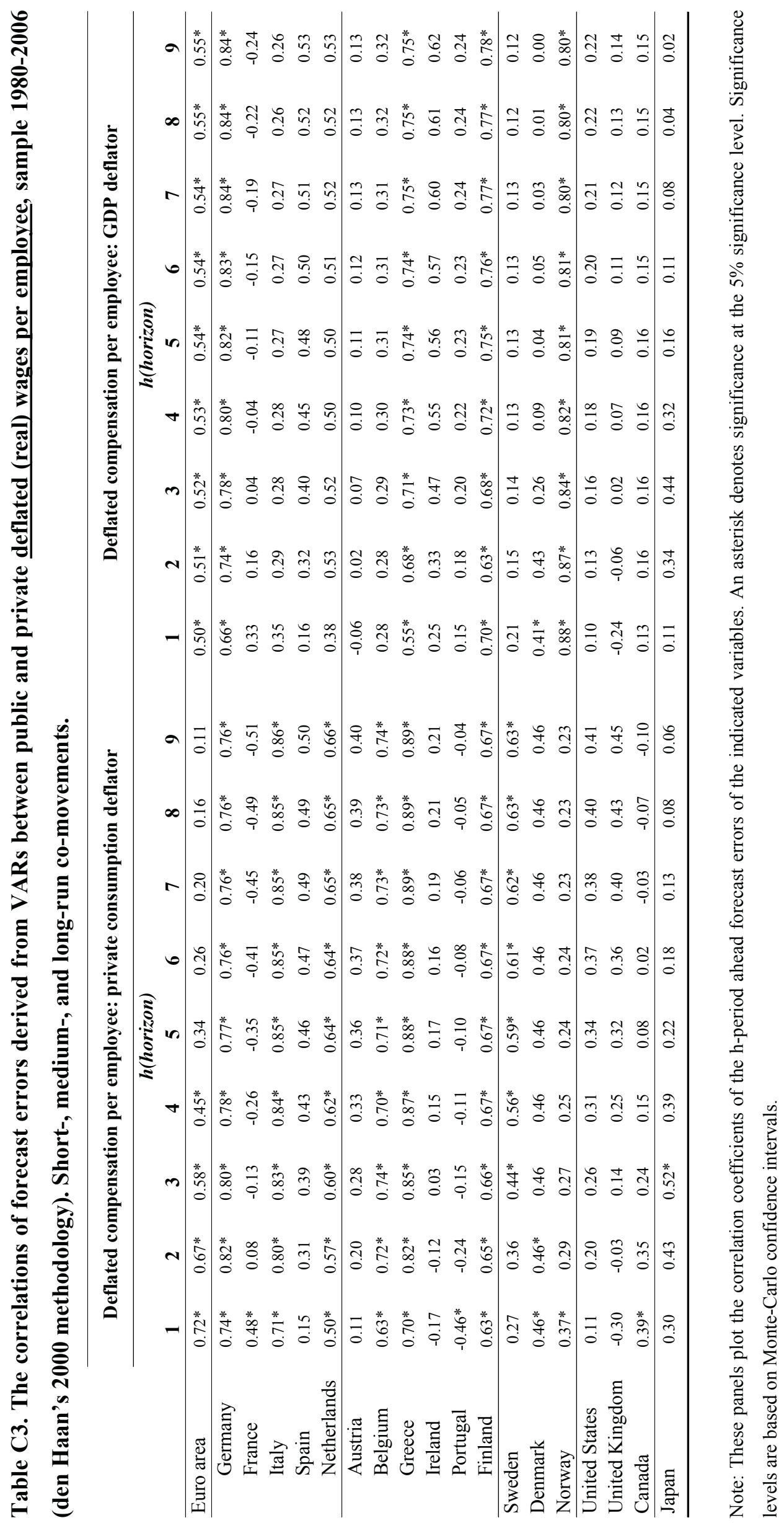


Table C4. Cointegration tests. Model with price level. Annual data 1960-2006.

Nominal compensation per employee

(model with price level)

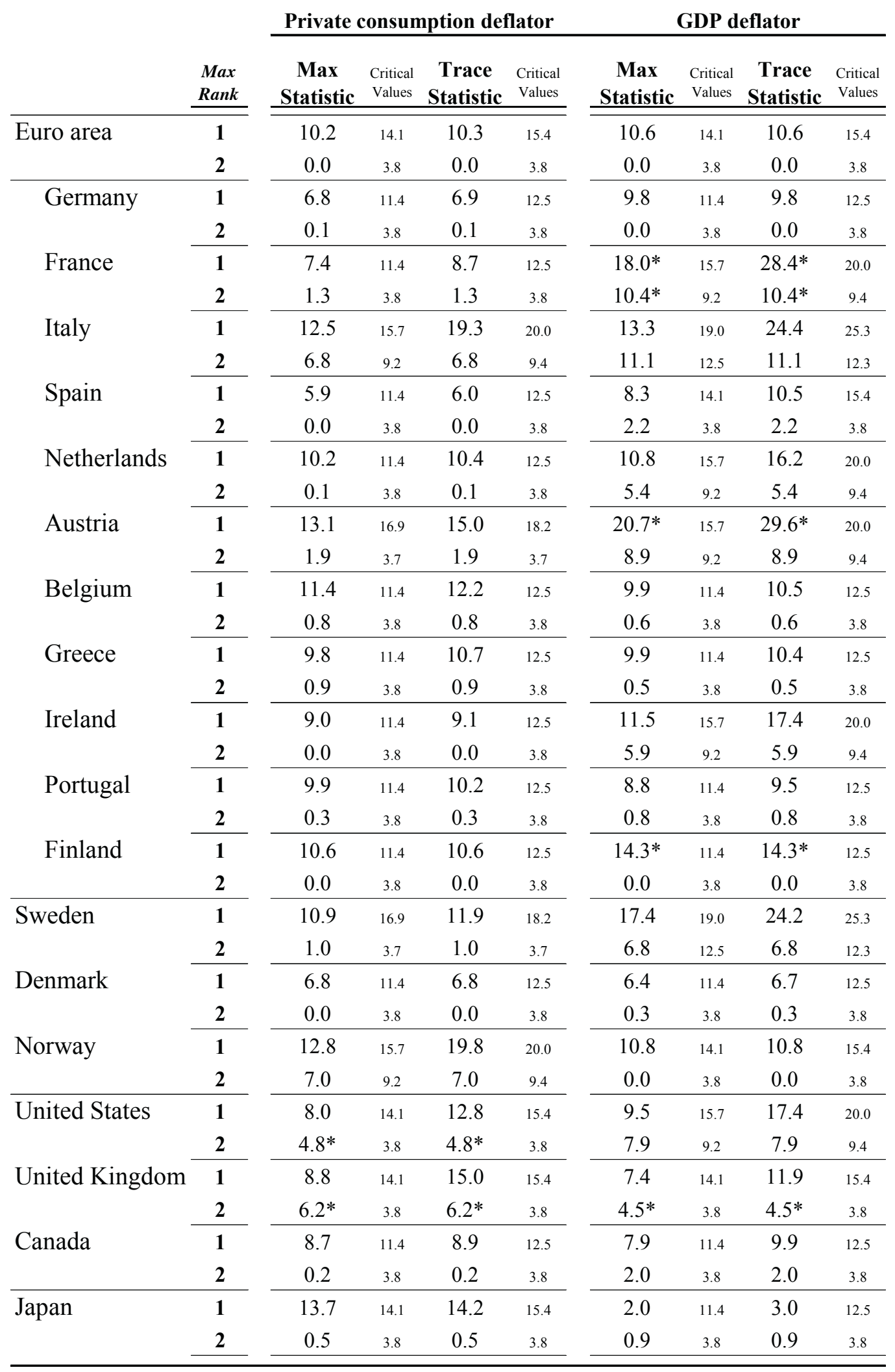

Note: an asterisk indicates significance at the $5 \%$ level. Osterwald-Lenum critical values for both the Maximum-eigenvalue and Trace test statistics. 
Appendix D.

Table D1. Granger Causality tests I: detrended variables. Annual data 1980-2006.

\begin{tabular}{|c|c|c|c|c|c|c|}
\hline \multirow[b]{4}{*}{ Euro area } & \multicolumn{2}{|c|}{$\begin{array}{l}\text { Nominal comp. } \\
\text { per employee }\end{array}$} & \multicolumn{4}{|c|}{$\begin{array}{l}\text { Nominal comp. per employee } \\
\text { (model including price level) }\end{array}$} \\
\hline & & & \multicolumn{2}{|c|}{$\begin{array}{c}\text { Private consumption } \\
\text { deflator }\end{array}$} & \multicolumn{2}{|c|}{ GDP deflator } \\
\hline & \multicolumn{2}{|c|}{$\begin{array}{l}\text { Public } \longrightarrow \text { Private } \\
\text { Public } \longleftarrow \text { Private }\end{array}$} & \multicolumn{2}{|c|}{$\begin{array}{l}\text { Public } \rightarrow \text { Private } \\
\text { Public } \leftarrow \text { Private } \\
\end{array}$} & \multicolumn{2}{|c|}{$\begin{array}{l}\text { Public } \rightarrow \text { Private } \\
\text { Public } \leftarrow \text { Private }\end{array}$} \\
\hline & $\longrightarrow$ & $\leftarrow$ & $\longrightarrow$ & $\leftarrow$ & $\longrightarrow$ & $\longleftarrow$ \\
\hline First difference & 0 & 0 & 0 & 0 & 0 & 0 \\
\hline Other filters & 7 & 6 & 6 & 6 & 6 & 6 \\
\hline Germany & - & $\longleftarrow$ & - & $\leftarrow$ & $\longrightarrow$ & - \\
\hline First difference & 0 & 1 & 0 & 1 & 0 & 0 \\
\hline Other filters & 5 & 7 & 4 & 6 & 6 & 3 \\
\hline France & - & $\leftarrow$ & $\longrightarrow$ & $\leftarrow$ & - & $\longleftarrow$ \\
\hline First difference & 0 & 0 & 1 & 1 & 1 & 0 \\
\hline Other filters & 3 & 6 & 6 & 8 & 4 & 6 \\
\hline Italy & - & - & - & - & - & - \\
\hline First difference & 0 & 1 & 0 & 0 & 0 & 0 \\
\hline Other filters & 0 & 4 & 4 & 2 & 5 & 2 \\
\hline Spain & $\longrightarrow$ & $\leftarrow$ & $\longrightarrow$ & - & $\longrightarrow$ & - \\
\hline First difference & 1 & 1 & 1 & 0 & 1 & 0 \\
\hline Other filters & 8 & 7 & 6 & 5 & 9 & 4 \\
\hline Netherlands & - & $\leftarrow$ & - & $\leftarrow$ & - & - \\
\hline First difference & 0 & 0 & 0 & 0 & 0 & 0 \\
\hline Other filters & 3 & 6 & 0 & 6 & 0 & 4 \\
\hline Austria & - & $\leftarrow$ & - & $\leftarrow$ & - & $\longleftarrow$ \\
\hline First difference & 0 & 1 & 0 & 1 & 0 & 1 \\
\hline Other filters & 2 & 9 & 2 & 8 & 2 & 7 \\
\hline Belgium & - & - & - & - & - & - \\
\hline First difference & 0 & 0 & 0 & 0 & 0 & 0 \\
\hline Other filters & 0 & 4 & 5 & 3 & 3 & 3 \\
\hline Greece & - & $\leftarrow$ & - & $\leftarrow$ & - & - \\
\hline First difference & 0 & 1 & 0 & 1 & 0 & 0 \\
\hline Other filters & 1 & 8 & 2 & 7 & 2 & 3 \\
\hline Ireland & - & $\leftarrow$ & $\longrightarrow$ & - & $\longrightarrow$ & $\longleftarrow$ \\
\hline First difference & 0 & 1 & 0 & 0 & 0 & 1 \\
\hline Other filters & 2 & 7 & 7 & 4 & 8 & 5 \\
\hline Portugal & - & - & $\longrightarrow$ & - & - & $\longleftarrow$ \\
\hline First difference & 0 & 1 & 1 & 0 & 0 & 0 \\
\hline Other filters & 2 & 4 & 6 & 5 & 4 & 6 \\
\hline Finland & $\longrightarrow$ & $\leftarrow$ & $\longrightarrow$ & $\leftarrow$ & - & $\longleftarrow$ \\
\hline First difference & 0 & 1 & 1 & 1 & 0 & 0 \\
\hline Other filters & 6 & 7 & 9 & 9 & 3 & 8 \\
\hline Sweden & - & $\leftarrow$ & - & - & - & - \\
\hline First difference & 0 & 1 & 1 & 0 & 0 & 0 \\
\hline Other filters & 4 & 9 & 3 & 5 & 2 & 4 \\
\hline Denmark & - & $\leftarrow$ & - & $\leftarrow$ & - & $\leftarrow$ \\
\hline First difference & 0 & 1 & 0 & 0 & 0 & 1 \\
\hline Other filters & 1 & 8 & 1 & 7 & 4 & 7 \\
\hline Norway & $\longrightarrow$ & - & $\longrightarrow$ & - & $\longrightarrow$ & - \\
\hline First difference & 1 & 0 & 1 & 0 & 1 & 0 \\
\hline Other filters & 8 & 1 & 5 & 3 & 8 & 0 \\
\hline United States & - & - & - & - & - & - \\
\hline First difference & 0 & 0 & 0 & 0 & 0 & 0 \\
\hline Other filters & 3 & 4 & 2 & 4 & 3 & 3 \\
\hline United Kingdom & - & $\leftarrow$ & - & $\leftarrow$ & - & $\longleftarrow$ \\
\hline First difference & 0 & 1 & 0 & 1 & 0 & 1 \\
\hline Other filters & 2 & 6 & 1 & 5 & 4 & 8 \\
\hline Canada & - & - & - & - & $\longrightarrow$ & - \\
\hline First difference & 0 & 0 & 0 & 0 & 0 & 1 \\
\hline Other filters & 4 & 2 & 5 & 4 & 7 & 4 \\
\hline Japan & $\longrightarrow$ & - & $\longrightarrow$ & $\longleftarrow$ & $\longrightarrow$ & $\longleftarrow$ \\
\hline First difference & 0 & 1 & 0 & 1 & 0 & 1 \\
\hline Other filters & 9 & 1 & 9 & 5 & 8 & 10 \\
\hline
\end{tabular}


Appendix E.

Table E1. Granger Causality tests II: VARs in levels. Annual data 1960-2006.

\begin{tabular}{|c|c|c|c|c|c|c|c|c|c|c|c|c|c|c|c|}
\hline & \multirow{2}{*}{\multicolumn{5}{|c|}{$\begin{array}{l}\text { Nominal compensation per } \\
\text { employee }\end{array}$}} & \multirow{2}{*}{\multicolumn{10}{|c|}{$\begin{array}{l}\text { Nominal compensation per employee } \\
\text { (model with price level) }\end{array}$}} \\
\hline & & & & & & & & & & & & & & & \\
\hline & & & & & & \multicolumn{5}{|c|}{ Private consumption deflator } & \multicolumn{5}{|c|}{ GDP deflator } \\
\hline & \multicolumn{3}{|c|}{$\begin{array}{l}\text { VAR lag order } \\
\text { selection }\end{array}$} & & \multirow{2}{*}{$\begin{array}{c}\begin{array}{c}\text { Public } \\
\text { Private }\end{array} \\
p \text {-value } \\
\text { VAR }(\mathrm{p}+1)\end{array}$} & \multicolumn{3}{|c|}{$\begin{array}{l}\text { VAR lag order } \\
\text { selection }\end{array}$} & \multirow{2}{*}{$\begin{array}{c}\begin{array}{c}\text { Public } \rightarrow \\
\text { Private }\end{array} \\
\begin{array}{c}p \text {-value } \\
\operatorname{VAR}(\mathrm{p}+1)\end{array}\end{array}$} & \multirow{2}{*}{$\begin{array}{c}\begin{array}{c}\text { Public } \leftarrow \\
\text { Private }\end{array} \\
p \text {-value } \\
\text { VAR }(\mathrm{p}+1)\end{array}$} & \multicolumn{3}{|c|}{$\begin{array}{l}\text { VAR lag order } \\
\text { selection }\end{array}$} & & $\begin{array}{c}\text { Public } \\
\text { Private }\end{array}$ \\
\hline & & $\begin{array}{l}\mathrm{HQC} A \\
\text { der } p\end{array}$ & & & & & $\begin{array}{l}\mathrm{HQC} A \\
\operatorname{derp}\end{array}$ & & & & & IQC & & & $\begin{array}{c}p \text {-value } \\
\operatorname{VAR}(\mathrm{p}+1)\end{array}$ \\
\hline Euro area & 2 & 2 & 2 & 0.983 & $0.018 * *$ & 1 & 2 & 2 & 0.557 & $0.025^{* *}$ & 1 & 2 & 2 & 0.557 & $0.055^{*}$ \\
\hline Germany & 2 & 2 & 2 & 0.744 & $0.000 * * *$ & 1 & 1 & 1 & 0.298 & 0.176 & 1 & 1 & 2 & 0.262 & $0.003 * * *$ \\
\hline France & 2 & 2 & 2 & 0.231 & $0.000^{* * *}$ & 2 & 2 & 2 & $0.079 *$ & $0.002^{* * *}$ & 2 & 2 & 2 & $0.016^{* *}$ & $0.035^{* *}$ \\
\hline Italy & 1 & 2 & 2 & $0.005^{* * *}$ & $0.000 * * *$ & 2 & 2 & 2 & 0.560 & $0.030^{* *}$ & 2 & 2 & 2 & $0.086^{*}$ & 0.467 \\
\hline Spain & 2 & 2 & 2 & 0.821 & $0.000^{* * *}$ & 2 & 2 & 2 & 0.970 & 0.842 & 2 & 2 & 2 & 0.874 & 0.353 \\
\hline Netherlands & 2 & 2 & 2 & $0.004 * * *$ & 0.275 & 2 & 2 & 2 & $0.000^{* * *}$ & $0.001 * * *$ & 2 & 2 & 2 & $0.017 * *$ & $0.006^{* * *}$ \\
\hline Austria & 2 & 2 & 2 & 0.315 & $0.004 * * *$ & 2 & 2 & 2 & 0.262 & 0.392 & 2 & 2 & 2 & 0.105 & 0.475 \\
\hline Belgium & 1 & 1 & 1 & 0.287 & $0.060^{*}$ & 1 & 2 & 2 & 0.500 & 0.292 & 1 & 2 & 2 & 0.653 & 0.154 \\
\hline Greece & 1 & 2 & 2 & $0.006^{* * *}$ & $0.000^{* * *}$ & 2 & 2 & 2 & 0.193 & $0.013^{* *}$ & 2 & 2 & 2 & 0.258 & $0.068^{*}$ \\
\hline Ireland & 2 & 2 & 2 & 0.175 & 0.272 & 2 & 2 & 2 & $0.000 * * *$ & 0.754 & 2 & 2 & 2 & $0.019 * *$ & $0.028^{* *}$ \\
\hline Portugal & 1 & 2 & 2 & $0.015^{* *}$ & $0.000 * * *$ & 1 & 2 & 2 & 0.174 & $0.002^{* * * *}$ & 1 & 1 & 2 & 0.486 & $0.001 * * *$ \\
\hline Finland & 2 & 2 & 2 & $0.010 * *$ & $0.000^{* * *}$ & 1 & 1 & 2 & $0.014 * *$ & $0.037 * *$ & 2 & 2 & 2 & $0.086^{*}$ & 0.660 \\
\hline Sweden & 1 & 1 & 1 & $0.044 * *$ & $0.000 * * *$ & 1 & 1 & 1 & 0.161 & $0.000 * * *$ & 1 & 1 & 1 & 0.527 & $0.014 * *$ \\
\hline Denmark & 1 & 2 & 2 & $0.017 * *$ & $0.025^{* *}$ & 2 & 2 & 2 & $0.003 * * *$ & $0.076^{*}$ & 2 & 2 & 2 & 0.317 & $0.019^{* *}$ \\
\hline Norway & 1 & 2 & 2 & 0.911 & 0.373 & 1 & 2 & 2 & 0.282 & 0.616 & 2 & 2 & 2 & 0.548 & 0.534 \\
\hline United States & 2 & 2 & 2 & 0.973 & $0.000 * * *$ & 2 & 2 & 2 & 0.725 & $0.000^{* * *}$ & 2 & 2 & 2 & 0.723 & $0.000^{* * *}$ \\
\hline United Kingdom & 1 & 2 & 2 & 0.589 & $0.006^{* * *}$ & 1 & 2 & 2 & 0.448 & $0.007 * * *$ & 1 & 1 & 2 & 0.624 & $0.027 * *$ \\
\hline Canada & 1 & 2 & 2 & 0.533 & $0.017 * *$ & 1 & 2 & 2 & 0.188 & $0.006^{* * *}$ & 2 & 2 & 2 & $0.006^{* * *}$ & 0.203 \\
\hline Japan & 2 & 2 & 2 & 0.660 & $0.000 * * *$ & 1 & 1 & 2 & $0.051^{*}$ & $0.000 * * *$ & 2 & 2 & 2 & 0.101 & $0.000^{* * *}$ \\
\hline
\end{tabular}

Note: An asterisk denotes significance at the $10 \%$ significance level, two asterisks denote significance at the $5 \%$ significance level, three asterisks denote significance at the $1 \%$ significance level. 


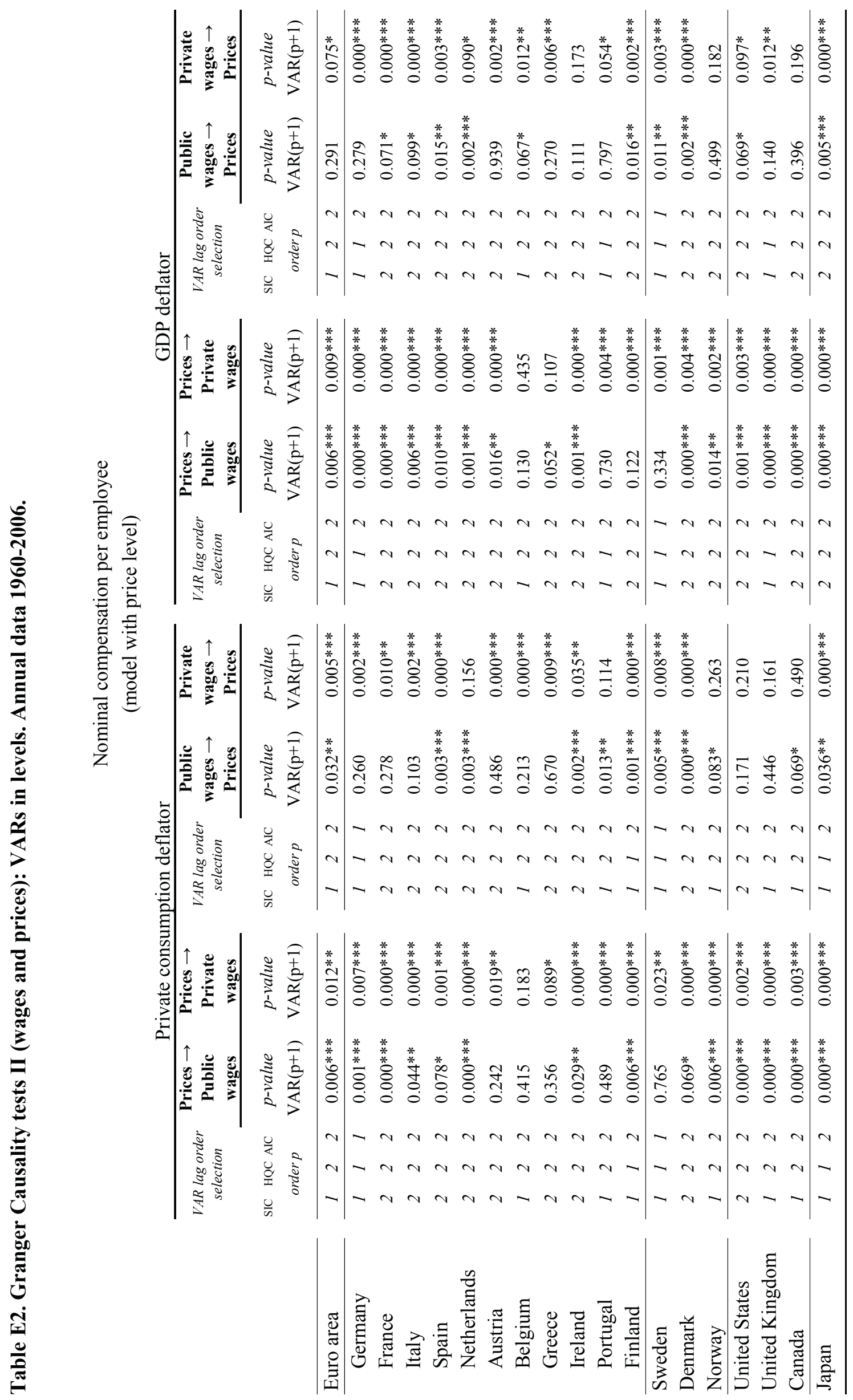




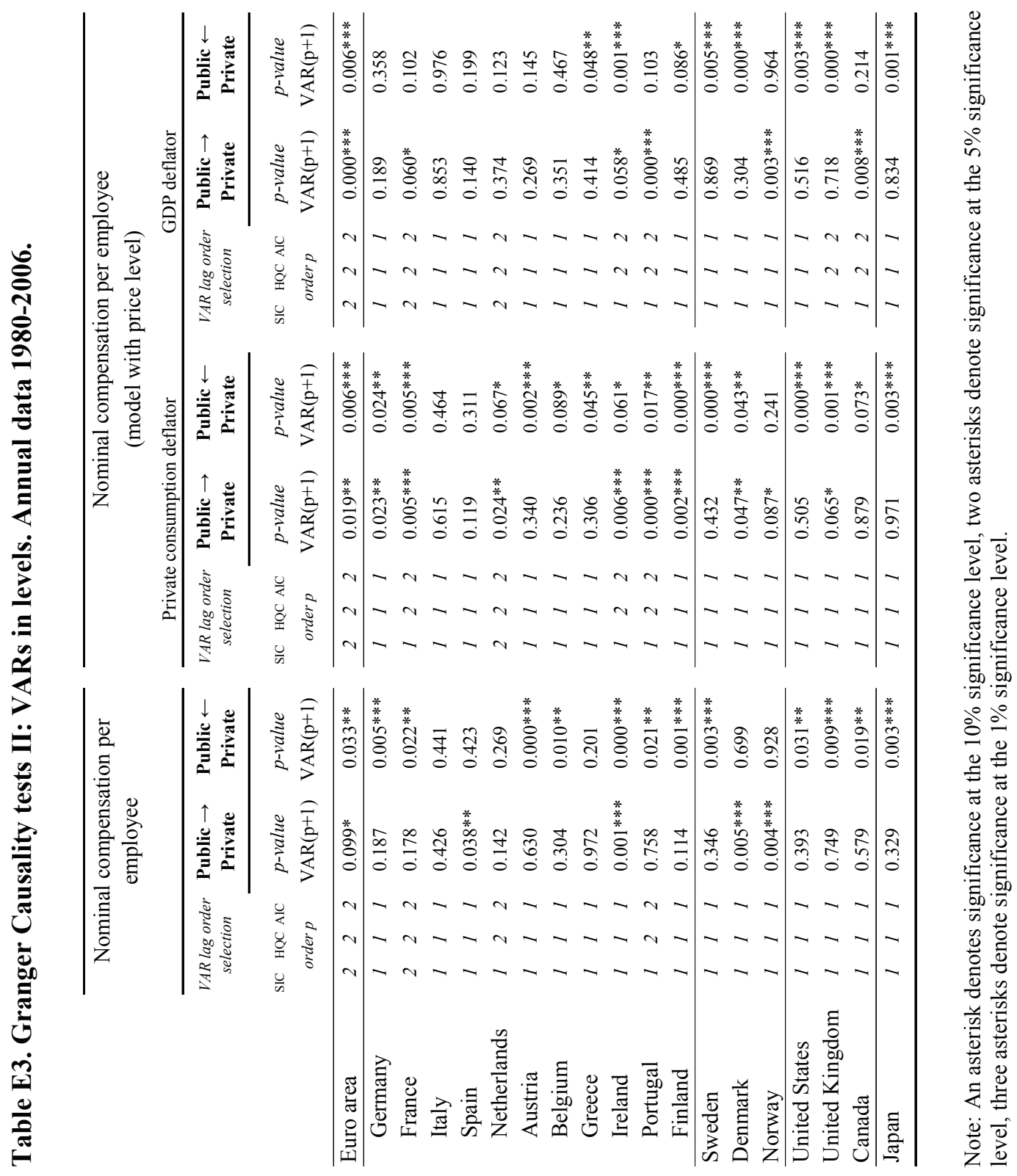




\section{Appendix F.}

Table F1. Institutional variables used in the empirical analysis of section 6.3.

\begin{tabular}{|l|l|}
\hline Independent variable & Source \\
\hline Index of bargaining coordination and centralisation & Ochel (2000) based on OECD \\
\hline Employment protection legislation & $\begin{array}{l}\text { Allard (2005) based on OECD labour market } \\
\text { statistics database (lmsd) }\end{array}$ \\
\hline Union membership/ employment & Udnet based on OECD lmsd and Visser (2006) \\
\hline Index of globalisation & Dreher (2006) \\
\hline Product market regulation index & Conway, Janod and Nicoletti (2005) \\
\hline Government involvement in collective bargaining & DuCaju et al. (2008) \\
\hline High coverage of indexation (75-100\%) & DuCaju et al. (2008) \\
\hline $\begin{array}{l}\text { Dominant level of collective bargaining: sectoral, } \\
\text { occupational national, regional, company-level }\end{array}$ & DuCaju et al. (2008) \\
\hline
\end{tabular}




\section{European Central Bank Working Paper Series}

For a complete list of Working Papers published by the ECB, please visit the ECB's website (http://www.ecb.europa.eu).

923 "Resuscitating the wage channel in models with unemployment fluctuations" by K. Christoffel and K. Kuester, August 2008.

924 "Government spending volatility and the size of nations" by D. Furceri and M. Poplawski Ribeiro, August 2008.

925 "Flow on conjunctural information and forecast of euro area economic activity" by K. Drechsel and L. Maurin, August 2008.

926 "Euro area money demand and international portfolio allocation: a contribution to assessing risks to price stability" by R. A. De Santis, C. A. Favero and B. Roffia, August 2008.

927 “Monetary stabilisation in a currency union of small open economies” by M. Sánchez, August 2008.

928 "Corporate tax competition and the decline of public investment" by P. Gomes and F. Pouget, August 2008.

929 "Real convergence in Central and Eastern European EU Member States: which role for exchange rate volatility?" by O. Arratibel, D. Furceri and R. Martin, September 2008.

930 "Sticky information Phillips curves: European evidence" by J. Döpke, J. Dovern, U. Fritsche and J. Slacalek, September 2008.

931 “International stock return comovements” by G. Bekaert, R. J. Hodrick and X. Zhang, September 2008.

932 "How does competition affect efficiency and soundness in banking? New empirical evidence" by K. Schaeck and M. Čihák, September 2008.

933 "Import price dynamics in major advanced economies and heterogeneity in exchange rate pass-through" by S. Dées, M. Burgert and N. Parent, September 2008.

934 "Bank mergers and lending relationships" by J. Montoriol-Garriga, September 2008.

935 "Fiscal policies, the current account and Ricardian equivalence" by C. Nickel and I. Vansteenkiste, September 2008.

936 "Sparse and stable Markowitz portfolios" by J. Brodie, I. Daubechies, C. De Mol, D. Giannone and I. Loris, September 2008.

937 "Should quarterly government finance statistics be used for fiscal surveillance in Europe?" by D. J. Pedregal and J. J. Pérez, September 2008.

938 "Channels of international risk-sharing: capital gains versus income flows" by T. Bracke and M. Schmitz, September 2008.

939 "An application of index numbers theory to interest rates" by J. Huerga and L. Steklacova, September 2008.

940 "The effect of durable goods and ICT on euro area productivity growth?" by J. Jalava and I. K. Kavonius, September 2008.

94I “The euro's influence upon trade: Rose effect versus border effect” by G. Cafiso, September 2008.

942 "Towards a monetary policy evaluation framework" by S. Adjemian, M. Darracq Pariès and S. Moyen, September 2008. 
943 "The impact of financial position on investment: an analysis for non-financial corporations in the euro area" by C. Martinez-Carrascal and A. Ferrando, September 2008.

944 "The New Area-Wide Model of the euro area: a micro-founded open-economy model for forecasting and policy analysis" by K. Christoffel, G. Coenen and A. Warne, October 2008.

945 "Wage and price dynamics in Portugal” by C. Robalo Marques, October 2008.

946 “Macroeconomic adjustment to monetary union” by G. Fagan and V. Gaspar, October 2008.

947 "Foreign-currency bonds: currency choice and the role of uncovered and covered interest parity" by M. M. Habib and M. Joy, October 2008.

948 "Clustering techniques applied to outlier detection of financial market series using a moving window filtering algorithm” by J. M. Puigvert Gutiérrez and J. Fortiana Gregori, October 2008.

949 “Short-term forecasts of euro area GDP growth” by E. Angelini, G. Camba-Méndez, D. Giannone, L. Reichlin and G. Rünstler, October 2008.

950 "Is forecasting with large models informative? Assessing the role of judgement in macroeconomic forecasts" by R. Mestre and P. McAdam, October 2008.

951 "Exchange rate pass-through in the global economy: the role of emerging market economies" by M. Bussière and T. Peltonen, October 2008.

952 "How successful is the G7 in managing exchange rates?" by M. Fratzscher, October 2008.

953 "Estimating and forecasting the euro area monthly national accounts from a dynamic factor model" by E. Angelini, M. Bańbura and G. Rünstler, October 2008.

954 “Fiscal policy responsiveness, persistence and discretion” by A. Afonso, L. Agnello and D. Furceri, October 2008.

955 “Monetary policy and stock market boom-bust cycles" by L. Christiano, C. llut, R. Motto and M. Rostagno, October 2008.

956 "The political economy under monetary union: has the euro made a difference?" by M. Fratzscher and L. Stracca, November 2008.

957 "Modeling autoregressive conditional skewness and kurtosis with multi-quantile CAViaR" by $\mathrm{H}$. White, T.-H. Kim, and S. Manganelli, November 2008.

958 “Oil exporters: in search of an external anchor” by M. M. Habib and J. Stráský, November 2008.

959 “What drives U.S. current account fluctuations?” by A. Barnett and R. Straub, November 2008.

960 "On implications of micro price data for macro models" by B. Maćkowiak and F. Smets, November 2008.

96 I "Budgetary and external imbalances relationship: a panel data diagnostic" by A. Afonso and C. Rault, November 2008.

962 "Optimal monetary policy and the transmission of oil-supply shocks to the euro area under rational expectations" by S. Adjemian and M. Darracq Pariès, November 2008.

963 "Public and private sector wages: co-movement and causality" by A. Lamo, J. J. Pérez and L. Schuknecht, November 2008. 
